MEIEORITES AND THE EARLY SOLAR SYSTEM

Edward Anders

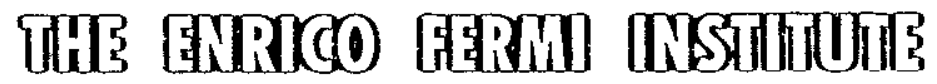

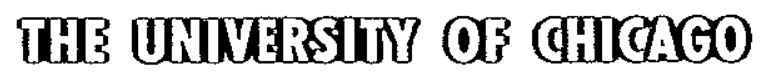

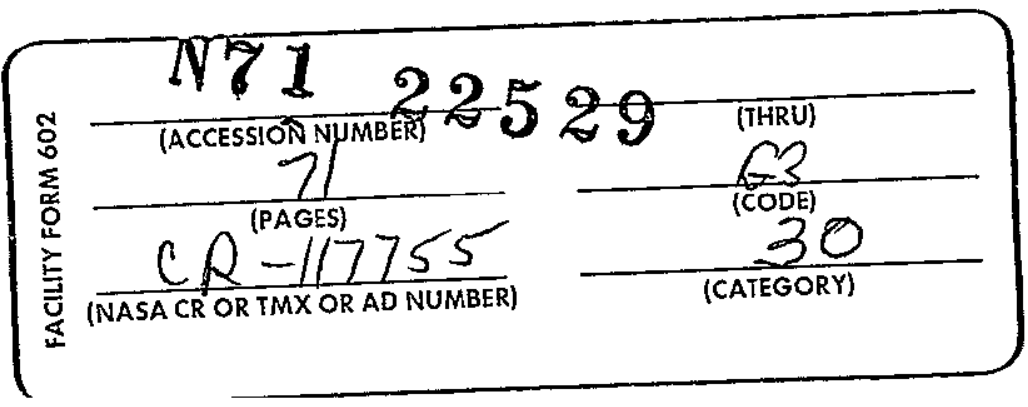




\section{METEORITES AND THE EARLY SOLAR SYSTEM}

\section{Edward Anders}

Enrico Fermi Institute and Department of Chemistry University of Chicago, Chicago, IIIinois $60637^{*}$ and

Physikalisches Institut Universität Bern, Switzerland

To be Published in Annual Review of Astronomy and Astrophysics Volume 9

Submitted: December 1970

AEC Contract AT (11-1) -382

NASA Grant NGR 14-001-010 commission für Weltraumforschung der Schweizerischen Naturforschenden Gesellschaft EFI -70-71

*Permanent Address 


\section{INTRODUCTION}

Meteorites contain far more information about the early solar system than was once believed. Chondrites, as the most. primitive meteorites, have of course long.served as the basis of the "cosmic" (better "solar-system")" abundance curve; on the assumption that they represent-well-mixed rubble from the inner.solar system. But during the last decade another view has gained ascendancy: that chondrites are an original and relatively unaltered condensate from the solar nebula. If. this is true, then chondrites contain a unique archeological record of physical and chemical conditions in the solar nebula. It is the job of the meteoriticist to decipher this record; to translate structure, composition, and mineralogy into temperature, pressure, time, and chemical environment.

By a fortunate coincidence, observational and theoretical work on proto-stars has advanced to the point where detailed estimates of some of these same parameters can be made. To be sure, the meteoritic evidence is sometimes ambiguous and at best applies to only one solar system. Nonetheless it appears that comparisons between meteoritic and astronomical observations are becoming increasingly fruitful..

$\because$ The origin of meteorites has been vigorously debated during the last decade. The prevailing view at present is that most (or all) meteorites come' from the asteroid belt. But a cometary origin of some types (e.g. carbonaceous chondrites) remains 
an intriguing possibility. Thus meteorites contain clues to conditions at 2 to 4 a.u., perhaps also to those in the giant planet zone.

In this paper, I shall review the meteoritic evidence as of late 1970, emphasizing those properties that relate to the solar nebula. The paper begins with a glossary followed by brief sections on the classification of chondrites and the composition of primordial matter. The next section, comprising the major part of the paper, reviews the processes that may have influenced the chemistry and mineralogy of chondrites. The following section discusses the time scale of meteorite evolution. The last section sums up the principal conclusions and reviews the implications for planetary cosmogony.

Any decipherment of an archeological record involves some subjectivity. I shall try to follow the rules set down in my previous reviews (Anders, 1964, 1968): (a) any interpretation must be consistent with all available evidence; and (b), of * several alternative interpretations, the simplest one is to be preferred. It is not obvious that the latter rule (Occam's principle) is applicable to meteorites. Authorities as eminent as Urey (1967) and Suess (1965) believe that meteorites had a very complicated history; if this view is accepted then Occam's principle is not a valid guide. The reader is therefore referred to the above reviews for a different view of the same subject. 


\section{Glossary}

Chondrites. - Chondrites are stony meteorites containing chondrules, millimeter-sized silicate spherules that appear to be frozen droplets of a melt. They consist largely of olivine $\left[(\mathrm{Mg}, \mathrm{Fe})_{2} \mathrm{SiO}_{4}\right]$, pyroxene $\left[(\mathrm{Mg}, \mathrm{Fe}) \mathrm{SiO}_{3}\right]$, and plagioclase feldspar [solid solution of $\mathrm{CaAl}_{2} \mathrm{Si}_{2} \mathrm{O}_{8}$ and $\mathrm{NaAlSi}_{3} \mathrm{O}_{8}$ ]. In the more primitive chondrites, glass is often found in place of crystalline feldspar. (Special names exist for the end-members of the Fe-Mg solid solutions: $\mathrm{MgSiO}_{3}=$ enstatite; $\mathrm{FeSiO}_{3}=$ ferrosilite; $\mathrm{Mg}_{2} \mathrm{SiO}_{4}=$ forsterite; $\mathrm{Fe}_{2} \mathrm{SiO}_{4}=$ fayalite. ${ }_{\dddot{Z}}^{\text {We }}$ shall use them only in cases of absolute necessity).

Chondrules are embedded in a ground-mass or matrix. In the less primitive chondrites, the matrix is somewhat more finegrained than the chondrules, but otherwise has the same mineralogy and composition. Millimeter-sized particles of metal (nickeliron with $5-60 \% \mathrm{Ni}$ ) and troilite (FeS) are also present. In the more primitive chondrites, the matrix is very fine-grained (to $\sim 10^{-6} \mathrm{~cm}$ ) and richer in $\mathrm{Fe}^{2+}$ than the chondrules.

\section{Classification of Chondrites}

Of the four principal meteorite classes (chondrites, achondrites, irons, and stony irons), chondrites are undoubtedly the most primitive, containing all, non-volatile elements in approximately solar proportions. Nonetheless, there are welldefined differences among the five subclasses of chondrites. At last count, some 50-odd elements showed such abundance 
differences (Larimer and Anders, 1970), mostly subtle (10 to 50\%), but occasionally large (factors of 2 to 1000). A few of these differences may have been established in the meteorite parent bodies, but the majority seem to date back to the solar nebula. Let us review the classification of chondrites, and then explore the chemical differences one by one.

- The most up-to-date classification of chondrites is that of Van Schmus and Wood (1967). It retains the traditional subdivision into 5 major groups on the basis of chemical criteria: ratio of metallic to total iron; $\mathrm{Fe} / \mathrm{Si}$ and $\mathrm{Mg} / \mathrm{Si}$ ratios; degree of oxidation of iron as measured by $\mathrm{Fe}^{2+} /\left(\mathrm{Fe}^{2+}+\mathrm{Mg}^{2+}\right)$ ratio in silicates, etc. (Table 1). In addition, it subdivides each chemical group into a maximum of 6 "petrologic types" reflecting the extreme range of chondrule-matrix intergrowth. Chondrites with sharply delineated chondrules and submicron-sized, opaque. matrix are classified as types 2 or 3 ; those with less distinct chondrules and coarser-grained matrix, as progressively higher types, 4 to 6 . The classification is based on 10 petrographic criteria. A separate category, Type 1 , is reserved for the chondrule-free Type I carbonaceous chondrites.

An important distinction is only subtly hinted at in Table 1. Whereas ail 3 classes of ordinary chondrites are "isochemical", i.e. have essentially constant major element contents from Types 3 to $6, \mathrm{C}$ and $\mathrm{E}$ chondrites are not. The larger standard deviations in major element ratios reflect systematic compositional 
variations from the lower to the higher petrologic types.

Which of the properties in Table 1 were established in the solar nebula and which in the meteorite parent bodies? Though we have no foolproof criterion for deciding where a given feature arose, circumstantial evidence suggests that most of the chemical properties date back to the nebula (Larimer and Anders, 1967, 1.970; Keays et a1., 1971). On the other hand, some of the textural properties such as the increasing recrystallization from Types 2 to 6 seem to have developed in the meteorite parent bodies by sustained heating (thermal metamorphism;. Wood, 1962a; Dodd, 1969). Yet there exist certain correlations between chemical composition and petrologic type, and at least some of these apparently pre-date metamorphism. "For this reason, the petrologic classification, though ostensibly based on a postnebular feature, will be useful in our discussion.

\section{Composition of Primordial Matter}

It is almost an axiom that the solar nebula was well-mixed in an isotopic and elemental sense (Suess, 1965). Certainly no isotopic differences have yet been found that might be attributed to incomplete mixing of material with different nucleosynthetic histories (Anders, 1964; Arnold and Suess, 1969). Elemental differences have of course been observed (Table 1). All are explicable by chemical fractionations, however, and though the locale of such fractionation cannot be strictly specified, the pressures inferred in some cases $\left(1.0^{-4 \pm 2}\right.$ atm; Larimer and 
Anders, 1970) are more appropriate to the solar nebula than to an interstellar cloud. Moreover, it is unlikely that initial compositional differences could have persisted throughout the enormous ( $10^{13}$-fold) contraction from interstellar to nebular densities, even if interstellar grains had not been vaporized in the process. Thus we are probably justified in assuming that the solar nebula once had completely uniform elemental composition.

Granted this assumption, we can attempt to deduce this composition. Goles (1969) has likened the search for this "primordial" composition to the search for the Holy Grail. The analogy is apt insofar as fervor is concerned, though medieval bloodshed has been replaced by mere acrimony.

Most authors regard $\mathrm{Cl}$ chondrites as the closest available approximation of primordial solar-system matter. This point of view was opposed by Urey $(1964,1967)$ and Suess and Arnold (1969), on. the grounds that the abundance of iron in Cl chondrites was some 5-10 times higher than that in the solar photosphere. Anders (1964) reviewed the problem at some length and suggested that the photospheric value was in error because it led to various implausịble consequences. ${ }^{1}$ The issue was resolved by Garz and

1 Urey (1966, 1967) has accused me of "ignoring" or "neglecting" this problem although I devoted 11 pages of my 1964 review to it (pp. $644-650,700-703$ ). 
Kock (1969) who discovered a 10-fold error in the oscillator strengths of the FeI lines used for the solar abundance determinations. Excellent agreement now exists between the meteoritic value and all solar values, whether based on allowed or forbidden lines of FeI or FeII in the photosphere, or on coronal lines (Garz et al. , 1969, 1970; Baschek et a‥, 1970).

Even with the iron problem resolved, there remains the legitimate question just how closely $\mathrm{Cl}$ chondrites resemble primordial solar-system matter. Anders (1971) has considered the problem in detail, on the basis of nuclear abundance systematics, cosmic-ray and solar abundances, and cosmochemical fractionation processes. He concludes that the maximum difference between $\mathrm{Cl}$ and primordial abundances is a factor of 1.5 for groups of 10 or more elements and factors of 2 to 5 for individual elements. Obvious exceptions are highly volatile elements: $\mathrm{H}, \mathrm{C}, \mathrm{O}, \mathrm{N}$, and noble gases. It seems that $\mathrm{CI}$ chondrites (or abundance tables based thereon, e.g. Cameron, 1968) closely approximate the composition of primordial solarsystem matter.

\section{CHEMICAL PROCESSES IN THE EARLY SOLAR SYSTEM}

Separation of solids from gases is perhaps the most efficient cosmochemical fractionation process known (Suess, 1965). And there is good evidence for such separations during the formation of the meteorites and terrestrial planets. In terms of Brown's (1950) classification, these bodies consist largely of "earthy" material. The Earth, for example, contains 
on $1 \mathrm{y} \sim 10^{-4}$ its cosmic complement of "ices" (e.g. $\mathrm{H}_{2} \mathrm{O}$ ) and $\sim 10^{-7}$ to $10^{-12}$ of "gases" (e.g. noble gases). The depletion seems to have been governed by volatility and chemical reactivity rather than by molecular weight, because Ne (M.W. 20) is some 8 orders of magnitude more depleted than $\mathrm{H}_{2} \mathrm{O}$ (M.W. 18) (Urey, 1954).

During the last few years it has become apparent that many other, more subtle fractionations are also due to volatility. Let us therefore examine the condensation sequence of a cosmic gas, and use it as a frame of reference for interpreting the observed fractionations in meteorites. ${ }^{2}$

\section{Condensation Sequence of a Cosmic Gas}

Condensation sequences have been calculated by Urey (1952a, 1954), Lord (1965), Larimer (1967), Gilman (1969), and Clark et al. (1971). For an element E condensing in pure form, the basic condition for incipient condensation is that the partial pressure $p_{E}$ equal the vapor pressure $p_{v}$. At that point, the gas

2 Arrhenius and Alfvén (1970) have proposed a radically different alternative: that condensation took place not from the solar nebula, but from a partially ionized and excited low-density gas that was gradualiy added to the circumsolar region. This model offers novel and promising explanations for the abundance patterns of mercury and noble gases. However, its few remaining predictions happen to agree with those of the equilibrium condensation model. Detailed evaluation of the Arrhenius-Alfvén model will have to. await its further development. 
is saturated in $\mathrm{E}$. Since the gas consists largely of $\mathrm{H}_{2}, \mathrm{p}_{\mathrm{E}}$ can be approximated by $(2 \mathrm{E} / \mathrm{H}) \mathrm{p}_{\mathrm{t}}$, where $\mathrm{E}$ and $\mathrm{H}$ are the abundances of $\mathrm{E}$ and hydrogen in the gas, and $\mathrm{p}_{t}$, is the total pressure. The vapor pressure, in turn, is given by $p_{v}=A / T+B$, where $A$ and $B$ are constants varying from element to element. For elements condensing as compounds, the situation is similar, though the equations are more complex.

Two condensation diagrams based on the work of Larimer (1967 and unpublished) are shown in Figure I. They were calculated for a total pressure of $10^{-4}$ atm (a value appropriate to the asteroid belt) and Cameron's (1968) cosmic abundances. The upper diagram refers to the situation just discussed: condensation of pure elements and compounds. It applies to conditions of rapid cooling, where substances condense in successive layers without inter-diffusion or alloy formation. The lower diagram, on the other hand, assumes complete diffusional equilibration, with formation of alloys and solid solutions to the limit of solubility. The effect of such alloy formation is to raise the condensation temperatures of minor elements, and to widen their condensation intervals. Of course, all intermediate situations are possible.

A cooling gas of cosmic composition should thus condense in the following order. Below $2000^{\circ} \mathrm{K}$, some highly refractory compounds of $\mathrm{Ca}, \mathrm{Al}, \mathrm{Mg}$, and $\mathrm{Ti}$ appear, followed by magnesium silicates and nickel-iron at $\sim 1350$ to $\sim 1200^{\circ} \mathrm{K}$ and alkali silicates 
at 1100 to $1000^{\circ} \mathrm{K}$. Up to this point, some $90 \%$ of chondritic matter has condensed. Only.H, $\mathrm{C}, \mathrm{N}, \mathrm{O}, \mathrm{S}$ and some volatile trace elements still remain in the gas phase. At $680^{\circ} \mathrm{K}$ sulfur begins to condense by the reaction $\mathrm{Fe}+\mathrm{H}_{2} \mathrm{~S} \rightleftarrows \mathrm{FeS}+\mathrm{H}_{2}$, followed by $\mathrm{Pb}, \mathrm{Bi}, \mathrm{Tl}$, and In. Any remaining $\mathrm{Fe}$ reacts with $\mathrm{H}_{2} \mathrm{O}$ at $400^{\circ} \mathrm{K}$ to give $\mathrm{Fe}_{3} \mathrm{O}_{4}$. Finally, water is bound as hydrated silicates at some temperature between 250 and $400^{\circ} \mathrm{K}$.

Both diagrams assume that nucleation is instantaneous, so that the vapor never becomes supersaturated. This need not necessarily be so. Blander and his associates have pointed out that iron vapor, in particular, may supersaturate greatly, in which case the condensation would take a rather different course (Blander and Katz, 1967; Blander and Abdel-Gawad, 1969; Blander, 1970). We shall return to this alternative at appropriate times.

Next we shall discuss individual fractionation processes, arranged in order of falling temperature.

Fractionation of Refractory Elements.

Significantly, the elements which head the condensation sequence all happen to be fractionated among the major chondrite classes. The variation in $\mathrm{Mg} / \mathrm{Si}$ ratio has been known for a decade (Urey, 1961; Du Fresne and Anders, 1962) and has in fact been used as a classification criterion (Table 1). More recently, similar variations have been found for Al, Ca, Ti (Ahrens et al., 1969), Cr, Hf, La and lanthanides, Sc, Th, U, Y, and $\mathrm{Zr}$ (Larimer and Anders, 1970). When the data are normalized to Si, 
the abundances consistently increase from enstatite to ordinary to carbonaceous chondrites in the average ratio $0.56: 0.73:$. 1.00. All these elements are known to be highly refractory, and would be expected to concentrate in an early condensate or a volatilization residue.

Larimer and Anders (1970) have suggested that the trend from $C$ to $E$ chondrites reflects progressively greater loss of an early condensate $\left(\mathrm{MgAl}_{2} \mathrm{O}_{4}, \mathrm{CaTiO}_{3}, \mathrm{Mg}_{2} \mathrm{SiO}_{4}\right.$, etc.). The degree of loss cannot be uniquely determined from the data, because Si, the element used for normalization, is itself fractionated, and so are all other elements that might serve in its place. Assuming that $\mathrm{Cl}$ chondrites represent primordial composition, they deduce minimum losses of $14 \%$ and $27 \%$ of the total condensable matter from ordinary and enstati.te chondrites.

There is some evidence that material of the composition of this early condensate was present in the early solar system. Most C3 chondrites contain a few chondrules or irregular inclusions (up to several $\mathrm{cm}$ in diameter) of about the composition of the early condensate: $\mathrm{rich}$ in $\mathrm{Ca}, \mathrm{Al}, \mathrm{Ti}, \mathrm{Mg}$; poor in $\mathrm{Si}$ (Christophe, 1968, 1969; Keil et al., 1969; Marvin et al., 1970). And there exists astronomical evidence pointing to a fractionation of this sort. Herbig (1970a) noted that the interstellar gas is deficient in these same elements, and suggested that this might be due to partial condensation of refractories. Such condensation cannot have taken place at the low densities of interstellar 
space. Herbig therefore suggests that a major part of interstellar matter has once passed through solar nebulae. It would seem that partial condensation of refractories is a fairly universal feature, not limited to our own solar system.

There is some evidence that the least volatile metals ( Ir, Os, Re) were likewise fractionated with the early condensate (Larimer and Anders, 1970). Their abundances in iron meteorites vary by 3 orders of magnitude and are anti-correlated with those of equally reducible but more volatile elements, e.g. Pd and Ni (Yavnel", 1970). Similar though much smaller variations have been observed in chondrites (Baedecker et al., 1971).

The mechanism of the fractionation is still uncertain. Material rich in refractories can be produced either by partial condensation or by partial volatilization. The former would be expected if all interstellar grains were completely vaporized during collapse of the solar nebula (Cameron, 1962); and the. latter, if they were not. Once produced by whatever process, such material might settle toward the median plane of the nebula, thus becoming separated from the gas.

The fate of the "lost" refractories invites speculation. Some authors have proposed that the Earth and Moon are enriched in refractory elements ( $U, \mathrm{Th}, \mathrm{Ca}, \mathrm{Sr}$, and $\mathrm{Al}$ ) relative to chondrites (Gast, 1968; Ringwood and Essene, 1970). This might mean that the refractory material, being the oldest solid phase in the solar system, was preferentially accreted into asteroids 
and planets. However, the reality of this enrichment is in some doubt. Thermal history calculations by Hanks and Anderson (1969) suggest that the Earth is not enriched in $U$ and $T h$ relative to C-chondrites. The same conclusion has been reached by Larimer. (1971) from consideration of crustal abundances of 12 elements.

$$
\text { Metal-Silicate Fractionation. }
$$

Chondrites. - This fractionation manifests itself by variations in $\mathrm{Fe} / \mathrm{Si}$ ratio among major chondrite classes (Table 1): That this is not merely a fractionation of iron but of metal phase is shown by the parallel variation in other siderophile (= iron-loving) elements, such as $\mathrm{Ni}$, Co, $\mathrm{Au}$, etc. (Larimer and Anders, 1970). There has been much argument whether this fractionation represents loss of silicate from iron-poor material (e.g. L-chondrites; Urey and Craig, 1953) or loss of metal from iron-rich material (e.g. Cl or H-chonarites; Anders, 1964). Now that the discrepancy between the solar and the $\mathrm{Cl}$ chondrite abundance of iron has been eliminated, there is little reason " not to take the latter view.

Larimer and Anders (1970) have attempted to infer from chemical data various details of the metal-silicate fractionation: specifically, direction, extent, temperature, and redox conditions. The "raw" $\mathrm{Fe} / \mathrm{Si}$ and $\mathrm{Ni} / \mathrm{Si}$ ratios suggest that many $\mathrm{E}$ chondrites have been enriched in metal relative to $\mathrm{C}$ chondrites (Table 1 ). However, these ratios are misleading, because appreciable amounts 
of Si were lost during refractory-element fractionation. When a correction for this effect is applied, all chondrites turn out to have lower $\mathrm{Fe} / \mathrm{Si}$ ratios than do $\mathrm{Cl}$ chondrites. Thus the fractionation seems to have been uni-directional, involving only loss, but no gain, of metal. The maximum loss seems to have been $\sim 50 \%$.

The temperature during fractionation was estimated from abundances of volatile and siderophile trace elements, using the condensation diagram in Figure $I$. It turns out that Ir, Pd, Ni, $\mathrm{Co}, \mathrm{Au}$, and $\mathrm{Ge}$ are systematically less abundant in $\mathrm{L}$ chondrites than in $H$ chondrites, by a mean factor of 0.64 , while $G a$ and $S$. are about equally abundant in both classes. This implies that the first group of elements had already condensed on the metal when it was fractionated, while the latter group had not. The temperature during fractionation must thus lie below $1050^{\circ} \mathrm{K}$, the temperature for condensation of $90 \%$ of the Ge at $10^{-4} \mathrm{~atm}$. A 100-fold change in pressure shifts this temperature by $\pm 50^{\circ} \mathrm{K}$. For E chondrites, a corresponding value of $5985^{ \pm} 50^{\circ} \mathrm{K}$ was derived. planets. - Metal-silicate fractionations also seem to have occurred during formation of the terrestrial planets, as inferred by Noddack and Noddack (1930) and Urey (1952b) from the variations in density. Urey (1967) has estimated the following Fe/Si ratios for the planets: Mercury Venus Earth Mars Moon $\mathrm{Fe} / \mathrm{Si} \quad \sim 3.0 \quad \sim 1.0 \quad \sim 1.0 \quad 0.6 \quad 0.3$ 
These ratios must be regarded as approximate, because they are based on equations of state and planetary radii that are not always well-known. Bullen (1969) finds, for example, that identical compositions for Mars and the Earth are still within the realm of possibility. Nonetheless, there is no doubt that Mercury and the Moon differ substantially from the other 3 planets. Some uncertainty also arises from the assumption made in these calculations that planets and ordinary chondrites have silicate phases of identical composition, including $\mathrm{Fe}^{2+}$ content. This neglects possible differences in oxidation state and refractoryelement content. Indeed, Ringwood (1959, 1966) has tried to account for the density variations solely by differences in the degree of oxidation, while Levin (1957, 1963) postulated formation of metallized silicates at high pressures. However, neither hypothesis accounts for the high density of Mercury or for the variation in Fe/Si among various chondrite classes (Table I). Since these data clearly indicate that a metal-silicate fractionation took place in some parts of the solar system (0.4 a.u. and 2-4 a.u.), there seems to be little reason to assume that this process was inoperative between 0.7 and 1.5 a.u. Mechanism. - A variety of mechanisms have been proposed for the metal-silicate fractionation, based on differences in density, brittleness, volatility, magnetic susceptibility, etc. (Urey, 1952b, 1956; Wood, 1962b). The last two seem especially promising. At higher pressures (e.g. $210^{-2}$ atm), iron condenses 
ahead of $\mathrm{Mg}_{2} \mathrm{SiO}_{4}, \mathrm{MgSiO}_{3}$. If accretion is rapid, the innermost part of a growing planet may consist largely of nickel-iron. Such "inhomogeneous accretion" has recently been proposed for the terrestrial planets (Turekian and Clark, 1969). With pressures increasing toward the center of the solar nebula, one would expect metal contents to increase correspondingly, in accord with observation.

For the chondrites, a different mechanism suggests itself, which may or may not be applicable to the planets. The Ni-content of the metal during metal-silicate fractionation seems to have been about $6.4 \%$ and $5.2 \%$ for $O$ and $E$ chondrites (Larimer and Anders, 1970). The ferromagnetic Curie points for these alloys, $900^{\circ}$ and $940^{\circ} \mathrm{K}$, lie only slightly below the upper temperature limits of $\leq 1050^{\circ}$ and $\leq 985^{\circ} \mathrm{K}$ inferred from the Ge and $\mathrm{Ga}$ contents. Perhaps that is a coincidence but then it is hard to understand why the temperature had to fall $400^{\circ}$ after the refractory-element fractionation began. More probably, the relationship is causal, the fractionation being triggered by the appearance of ferromagnetism in the metal grains (Wood, 1962b).

Harris and Tozer (1967) estimated that ferromagnetism would enlarge the. capture cross section of metal grains by a factor of $2 \times 10^{4}$, causing them to aggregate rapidly to larger clumps. Separation from silicates might then be effected not only by differences in magnetic susceptibility but also by differences in size. Harris and Tozer's conclusions have been 
challenged by Banerjee (1967) on the grounds that particles in the size range considered by them $\left(10^{-4}\right.$ to $\left.10^{-3} \mathrm{~cm}\right)$ would be multi-domained and thus have only a negligible magnetic moment. At $950^{\circ} \mathrm{K}$, only particles between $1.8 \times 10^{-6}$ and $3.3 \times 10^{-5} \mathrm{~cm}$ would have moments large enough to permit significant magnetostatic attraction. However, this happens to be just the size range of $\mathrm{Fe}_{3} \mathrm{O}_{4}$ particles in primitive chondrites $\left[\sim 2 \times 10^{-6} \mathrm{~cm}\right.$ in Tieschitz

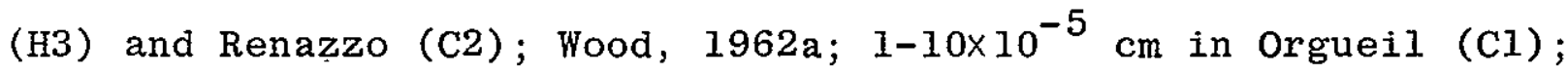
Kerridge, 1970, private communication]. Though we have no data on the original particle size in more recrystallized chondrites, it is not unreasonable to suppose that it was in the same range. In any case, even a rather inefficient process would suffice to account for the fractionations in Table 1 .

It would be interesting to know what became of the ironpoor material complementary to the inner planets. It may have been incorporated in the outer planets, expelled into interstellar space, or both.

Fractionation of Volatiles; Temperature and Pressure in the Solar Nebula.

Urey (1952a, b; 1954) was the first to note that volatile metals ( $\mathrm{Hg}, \mathrm{Cd}$, etc.) might serve as. "cosmothermometers" to determine the accretion temperature of meteorite parent bodies and the Earth. A careful analysis of the data then available showed no clear-cut evidence of significant depletion. Urey therefore concluded that both the Earth and meteorite parent 
bodies had accreted at a temperature of $\sim 300^{\circ} \mathrm{K}$, not far from the present black-body temperature at 1 a.u. This concept of "cold accretion" became firmly established in planetary cosmogony. But the situation has changed in subsequent years. Precision measurements by neutron activation analysis showed that nearly all elements considered volatile by Urey were in fact underabundant; some by factors as large as $10^{3}$, many others by smaller but nonetheless definite factors, e.g. 2 to 10 (Anders, 1964; Larimer and Anders, 1967). The new data lead to a different and much more detailed picture of accretion conditions in the solar nebula.

\section{Abundance Patterns. - At last count, some 31 volatile} elements appeared to be fractionated in chondrites. The simplest fractionation pattern is shown by carbonaceous chondrites (Figure 2).

'The elements are arranged in somewhat unconventional order, based on their depletion pattern in ordinary chondrites. Abundances decrease consistently from $\mathrm{Cl}$ to $\mathrm{C} 3$, and by constant factors as shown by the parallelism of the curves. ${ }^{3}$ This

3 Apparent exceptions occur at $\mathrm{Au}, \mathrm{Cl}$ and $\mathrm{Br}$, but past experience suggests that at least the last two may be due to sampling or analytical errors. Some points, especially for $\mathrm{Cl}$ 's, are based on only one or two measurements. The original version of this graph (Figures 16a,b in Anders, 1964) contained many more irregularities and gaps, which gradually disappeared in subsequent versions 
parallelism extends to the last five, elements on the graph, though their absolute depletion is very much greater.

Partial volatilization or condensation cannot account. for this pattern. The condensation curves in Figure 1 show clearly that there is no one temperature at which all elements will be condensed to the same fractional degree. Partial loss of a major phase (metal, sulfide, etc.) can also be ruled out, because the elements in Figure 2 differ greatly in geochemical character, and do not all reside in the same phase.

In order to account for these trends, it seems necessary to postulate that $\mathrm{C}$-chondrites are a mixture of two components: a high-temperature, volatile-free component, and a low-temperature, volatile-rich component (Wood, 1963; Anders, 1964). To explain the observed mean relative abundances $(\mathrm{Cl}: \mathrm{C} 2: \mathrm{C} 3=1.00: 0.55: 0.32)$, one must postulate $\sim 100 \%, \sim 55 \%$. and $32 \%$ low-temperature material in the three types.

(Figure 1, Larimer and Anders, 1967; Figure 3, Anders, 1968). In view of this secular trend, the irregularities at $\mathrm{Cl}$ and $\mathrm{Br}$ can perhaps be set aside for the time being.

The situation for $\mathrm{Au}$ is unclear. The overall fractionation is smaller than that of the other elements in Figure 2, and may be due to some combination of sampling and analytical errors, metal fractionation, etc. Moreover, Au is near the top of the condensation. sequence in Figure 1, where less complete depletion may be expected. 
There exists some circumstantial evidence in favor of this model. Broadly speaking, the mineraIs of carbonaceous chondrites can be divided into two groups: high-temperature (olivine, pyroxene, metal) and low-temperature (hydrated silicates, $\left.\mathrm{MgSO}_{4} ; \mathrm{S}, \mathrm{FeS}, \mathrm{Fe}_{3} \mathrm{O}_{4}\right)$. Significantly, the observed content of low-temperature minerals in the three types agrees closely with the postulated content of low-temperature fraction, and so does the ratio of matrix to chondrules. Cl's consist almost entirely of a fine-grained matrix of low-temperature minerals; c3's consist mainly of chondrules of high-temperature minerals. Furthermore, there is direct experimental evidence that chondrules and metal particles are depleted in volatile elements such as $\mathrm{Na}, \mathrm{Mn}$, and Ga, relative to matrix (Schmitt et al., 1965; Chou and Cohen, 1970). This suggests that the low-temperature fraction may be identical with the matrix, and the high-temperature fraction, with chondrules-plus-metal-particles. (In much of our subsequent discussion we shall use the shorter term "chondrules" for "chondrules plus.metal particles of comparable size").

Formation of chondrules and matrix. - Several possibilities exist for the formation of chondrules and matrix in the nebula. Wood $(1958,1962 \mathrm{~b}, 1963)$ suggested that they might represent material from two different condensation paths. Condensation of vapor to solid would give submicron-sized smoke (= matrix), while condensation of vapor to liquid would give droplets that might grow to millimeter-sized chondrules by coalescence. With $\sim 10^{5}$ times 
the radius:of.matrix grains, chondrules would have only $10^{-10}$ times the spècific surface area and hence be far less efficient collectors of volatiles under conditions where surface area is the governing factor (Figure 1a). Similarly, they would take $10^{10}$ times longer to reach diffusional equilibrium, and would thus be correspondingly less efficient where such equilibration is the determining factor (Figure $I b$ ).

Qualitatively Wood's model is most satisfactory, as it accounts for the main structural components of chondrites and their chemical differences. Quantitatively it is in some trouble, however. Condensation of magnesium silicates and nickel-iron from a cosmic gas requires pressures of 10 to $10^{3}$ atm (Suess, 1963; Wood, 1963), far higher than those expected in the solar nebula. One alternative is that the primordial condensate was entirely dust, and that some fraction of it was remelted to chondrules by electric discharges or shock waves (Whipple, 1966; Cameron, 1966). At pressures outside the liquid field of the phase diagram (i.e. <100 atm) molten droplets are of course unstable with respect to vapor, but if the remelting events are of a purely local scale, droplets may freeze before they have completely evaporated. Indeed, petrographers have agreed for over a century that the texture of chondrules indicates rapid crystálization.

Another alternative is that condensation did not proceed under equilibriúm conditions but involved supercooling and 
metastability. Blander and Katz (1967) have argued that liquids are easier to nucleate than solids; thus much of the silicate condensing. from the gas even at low pressures might be a metastable.liquid rather than a stable solid. Once crystallization is initiated by some chance event, the droplet would of course freeze rapidly.

Temperatures and Pressures. - Whatever the nature of the chondrule-forming process, it is instructive to compare the abundance patterns in chondrites with the predictions of the condensation diagram (Figure 1). For each of the two fractions, one can determine a "condensation temperature", defined as the temperature at which the solid grains ceased to equilibrate with the gas. (Under conditions of slow cooling, such equilibration would normally terminate with accretion. In that case, these temperatures may be interpreted as accretion temperatures). If condensation indeed proceeded according to Figure 1 , temperatures derived from different elements should be concordant, and consistent with other evidence.

. It appears that the high-temperature fraction is best explained in terms of Figure la; and the low-temperature fraction, in terms of. Figure 1b. This is not surprising in view of the differences in grain-size noted above.

The high-temperature fraction of $\mathrm{C}$ chondrites contains magnesium silicates and nickel-iron but is depleted in all elements from Mn on down. This is readily understood in terms of Figure la 
(but not $1 \mathrm{~b}$ ), for a condensation temperature of $1150-1250^{\circ} \mathrm{K}$. The low-temperature fraction, on the other hand, contains its full complement of even the highly volatile metals $\mathrm{Pb}, \mathrm{Bi}$, $\mathrm{T} 1$, and In. By either diagram, this implies an accretion temperature of $<400^{\circ} \mathrm{K}$. A value of the same order can be independently estimated from the presence of magnetite and hydrated silicates in $\mathrm{C}$ chondrites. The formation temperature of hydrated silicates is not well known and can only be roughly estimated as $300-350^{\circ} \mathrm{K}$. But the formation temperature of $\mathrm{Fe}_{3} \mathrm{O}_{4}$ is $400^{\circ} \mathrm{K}$ in a cosmic gas, and is independent of pressure (Urey, 1952b).

The ordinary chondrites'(dashed line in Figure 2) show a somewhat different trend, implying different condensation and accretion temperatures: [Only mean abundances are plotted here. Actually, the range of variation is quite large, chondrites of lower petrologic types generally being richer in volatile elements (Figure 4, Anders, 1968; Figure 1, Keays et al.., 1971)]. Nine elements from $\mathrm{Cu}$ to Se parallel the $\mathrm{C} 2$ and $\mathrm{C} 3$ curves. Though the 3 segments are not particularly flat in this region, their parallelism suggests that they reflect the same process. Any deviation from horizontality is probably due to errors in the Cl data used for normalization. It therefore seems likely that the ordinary chondrites, too, are a mixture of two components. The mean depletion factor between $\mathrm{Cu}$ and Se (using the latest data, J.C. Laul, private communication, and omitting Au; cf. footnote 3 ) is 0.24 , which suggests a matrix content of $24 \%$. 
The remaining elements deviate from the C2, 3 pattern. $\mathrm{Mn}, \mathrm{Na}, \mathrm{K}$, and $\mathrm{Rb}$ are essentially undepleted, while $\mathrm{Cs}$ and the elements from Te to TI show progressively greater depletion. The first trend suggests a lower condensation temperature of the hightemperature fraction, e.g. $1000^{\circ} \mathrm{K}$ vs $1150^{\circ}$ to $1250^{\circ} \mathrm{K}$, or a higher pressure. The second trend suggests a higher accretion temperature of the low-temperature fraction, within the region of partial condensation. Unfortunately, condensation curves are available for only 4 of the 13 strongly depleted elements (Ag, $\mathrm{Pb}, \mathrm{Bi}$, and $\mathrm{TI}$ ), owing to lack of thermodynamic data or complexity of chemical equilibria. The curve for a fifth element, In, has been estimated indirectly (Keays et $\underline{\text { al }}$, 1971).

Attempts to determine accretion temperatures from $\mathrm{Bi}, \mathrm{Tl}$, and In contents have been made by Larimer (1970) and Keays et al. (1971): Data for 11 L-chondrites are shown in Table 2 . Though there are minor discrepancies among the three "cosmothermometers", all three give fairly similar results. Accretion temperatures lie in a surprisingly narrow, 100-degree interval centered on $510^{\circ} \mathrm{K}$, and increase with petrologic type. Temperatures derived from $\mathrm{Pb}$ contents lie in the same range (Larimer, 1970).

Thé above temperature estimates are based on pressuredependent condensation curves and may thus be in error if the pressure differed greatly from the assumed value of $10^{-4}$ atm. However, at least for the L-chondrites the uncertainty in pressure is only two orders of magnitude in either direction, corresponding 
to a temperature exror of $+80,-60$ degrees (Keays et al., 1971). At pressures of $10^{-2}$ or $10^{-6}$ atm, calculated Bi-Tl correlation curves fit the data noticeably less well than at $10^{-4}$ atm. Moreover, all chondrites contain $\mathrm{FeS}$, whose formation temperature $\left(680^{\circ} \mathrm{K}\right)$ is pressure-independent. At a pressure of $10^{-2} \mathrm{~atm}$, the condensation curves of $\mathrm{Bi}$ and $\mathrm{TI}$ are shifted upward sufficiently to imply accretion temperatures greater than $680^{\circ} \mathrm{K}$ for the more strongly depleted Type 6's. Such meteorites then should contain no FeS, contrary to observation. Similarly, a lower limit of $10^{-6}$ to $10^{-7}$ atm can be inferred from the absence of $\mathrm{Fe}_{3} \mathrm{O}_{4}$ (formation temperature, $400^{\circ} \mathrm{K}$ ) from all but the least recrystallized and least-depleted Type 3's. Thus the pressure in the region of the L-chondrites apparently was $10^{-4 \pm 2}$ atm. It will be of interest to extend this treatment to other chondrite classes.

It is remarkable that temperatures as high as $500^{\circ} \mathrm{K}$ prevailed during accretion of the meteorite parent bodies, because the present black-body temperature at 2.8 a.u. is only $170^{\circ} \mathrm{K}$. Thus a powerful, transient heat source must have been present. One possibility is the Hayashi, stage of the Sun; another is the collapse stage of the nebula which would release vast amounts of gravitational potential energy over a short span of time (Cameron, 1962, 1963, 1969). Indeed, the temperatures inferred for the dust shells or disks surrounding proto-stars are of the right order: $\$ 1850$ to $350^{\circ} \mathrm{K}$ for VY Canis Majoris (Herbig, 1970b) and $\sim 850^{\circ} \mathrm{K}$ for $\mathrm{R}$ Monocerotis and other infrared stars (Low and Smith, 1966; Low, 1969). Perhaps it will soon be possible to 
compare time, temperature, and pressure estimates from meteorites with observational and theoretical data for proto-stars.

Planets. - There is some indication that the bulk of the accretion in the inner solar system took place between 500 and $700^{\circ} \mathrm{K}$. Only $5-10 \%$ of the ordinary chondrites are Type $3^{\prime} \mathrm{s}$ which accreted below $500^{\circ} \mathrm{K}$, and few if any meteorites have the FeSfree, but otherwise chondritic composition expected for material accreted above $680^{\circ} \mathrm{K}$. The Earth, too, seems to contain substantial amounts of FeS (Anderson et al., 1970), and resembles 04-06 chondrites in the abundance of volatile elements (Anders, 1968; Larimer, 1971). There are two limiting interpretations for this pattern: accretion at a constant temperature of $\sim 550^{\circ} \mathrm{K}$ or at falling temperatures from $>700$ to $\sim 350^{\circ} \mathrm{K}$. In the latter case, a large part of the volatiles may have been brought in as a thin veneer of carbonaceous-chondrite-like material, swept up by the Earth in the final stage of accretion.

4 We are continuing to use the term "accretion temperatures" although strictly speaking, these are temperatures of equilibration with the nebula. For a large planet, the former are much higher, owing to the release of gravitational potential energy during accretion. This has little effect on composition, though, because escape of volatiles during accretion of an earth-sized planet is unlikely. 
The Moon seems to be depleted in volatiles by another two orders of magnitude relative to the Earth (Ganapathy et al., 1970; Laul et al., 1970;..Anders, 1970).. In terms of the preceding two models, this may imply either accretion at a higher temperature (650 to $700^{\circ} \mathrm{K}$ ), or a much lower accretion efficiency in the final stages of formation, when volatile-rich material was being swept up. Ganapathy et al. (1970) and Anders (1970) have suggested that such inefficient accretion might result if the Moon formed in the Earth's neighborhood, but Singer and Bandermann (1970) have shown that quite the opposite effect would be expected, at least in the absence of gas.

Material balance. - The fate of the lost volatiles remains laregly undetermined. A few of the most volatile elements (In, Bi, $\mathrm{TI}, \mathrm{Cs}$, and $\mathrm{Br}$ ) are occasionally enriched in 03 chondrites. Such enrichment might be expected in the final stages of accretion. when the gas phase had become enriched in volatiles left. behind by. the previously accreted 04's-06's. An even more striking enrichment is shown by mercury, thought to be the most volatile of all metals (Urey, 1952b, 1954). It is enriched in C-chondrites by 1-2 orders of magnitude above cosmic levels and is only slightly depleted in O-chondrites (Reed and Jovanovic, 1967; Ehmann and Lovering, 1967). Larimer and Anders (1967) have tried to explain the "mercury paradox" by postulating the existence of a relatively 
involatile mercury compound, but Arrhenius and Alfvén (1970) have proposed an attractive alternative. If condensation took place from a partially ionized plasma, mercury, because of its high ionization potential, would be neutralized ahead of most other elements, thus becoming available for condensation at an earlier stage.

Some part of the volatiles may have been lost with the gases during dissipation of the solar nebula. Hence it seems unlikely that the average composition of all meteorites is close to cosmic. Meteorites apparently did not evolve in a closed system.

Other models. - Alternative explanations have been offered for the trace element depletion in ordinary chondrites. Tandon and Wasson (1968) suggested that the most volatile elements were contained largely in a third component, which becomes increasingly abundant in the lower petrologic types. Blander and Abdel-Gawad (1969) proposed instead a multi-component model, according to which each chondrite contains a variety of materials covering a range of grain sizes and condensation temperatures. Neither of these models predicts a simple relationship between abundance and temperature, let alone concordance of temperatures derived from different elements (Table 2). There are other objections to these more complex models (Keays et al., 1971), and it seems that there is no need at present to go beyond the simple twocomponent model. 
State of Oxidation

Chondrites differ strikingly in degree of oxidation, as reflected by the partition of iron between metal (plus sulfide) and silicates (Table 1). A convenient index of oxidation level is the iron content of the principal silicates, olivine and pyroxene. It is usually given as the atom percentage of $\mathrm{Fe}^{2+}$ in the mineral, using abbreviations Fa and Fs for the iron endmembers of the solid solution. Thus $\mathrm{Fa}_{18}$ means $\mathrm{Fe}^{2+} /\left(\mathrm{Fe}^{2+}+\mathrm{Mg}^{2+}\right)$ olivine $=0.18$.

Each of the five chondrite classes covers a narrow, characteristic range of iron contents (Table I, Column 6), separated by well-marked hiatuses. The equilibrated members of each class fall wholly within this range. The unequilibrated chondrites contain minerals of widely varying iron contents, but their mean iron content generaliy falls close to that of their equilibrated counterparts (Dodd et al., 1967).

Ordinary chondrites. - Silicates condensed from a hot cosmic gas are expected to have very low iron contents, less than 1\%. Fo'r this reason some authors have assumed that the high $\mathrm{Fe}^{2+}$ contents of ordinary chondrites were established in a non-cosmic environment, i.e. the meteorite parent bodies or a fractionated region of the solar nebula (Suess, 1964, 1965; Ringwood, 1966; Wood, 1967a). Bliander and Katz (1967), on the other hand, have pointed out that high $\mathrm{Fe}^{2+}$ contents might arise even by condensation from the solar nebula if the nucleation of 
metallic iron were kinetically inhibited. Under these conditions, the partial pressure of iron vapor remains orders of magnitude above the equilibrium value, causing a proportionate increase in the $\mathrm{Fe}^{2+}$ content of the silicates.

A simpler alternative is equilibration of the condensate with the nebular gas upon cooling. Under equilibrium conditions, iron-bearing olivine is produced by the reaction:

$$
\mathrm{MgSiO}_{3}+\mathrm{Fe}+\mathrm{H}_{2} \mathrm{O} \rightleftarrows \frac{1}{2} \mathrm{Mg}_{2} \mathrm{SiO}_{4}+\frac{1}{2} \mathrm{Fe}_{2} \mathrm{SiO}_{4}+\mathrm{H}_{2}
$$

The iron content of the pyroxene, in turn, is coupled to that of the olivine by the exchange equilibrium:

$$
\mathrm{Mg}_{2} \mathrm{SiO}_{4}+\mathrm{FeSiO}_{3} \rightleftarrows \mathrm{MgSiO}_{3}+\mathrm{Fe}_{2} \mathrm{SiO}_{4}
$$

Larimer (1968a) has considered these equilibria in detail and predicts the following olivine compositions in a solar gas of $\mathrm{H}_{2} / \mathrm{H}_{2} \mathrm{O}=500$ :

$\begin{array}{cccccccc}\mathrm{T}\left({ }^{\circ} \mathrm{K}\right) & 1400 & 1200 & 1000 & 800 & 700 & 600 & 500 \\ \mathrm{Fa}(\%) & 0.6 & 1 & 2 & 6 & 10 & 25 & 87\end{array}$

The olivine compositions in equilibrated ordinary chondrites ( $\mathrm{Fa}_{16}$ to $\mathrm{Fa}_{31}$, Table I) thus seem to point to equilibrium near $600^{\circ} \mathrm{K}$. Reaction rates are probably fast enough to permit establishment of equilibrium at these low temperatures. The equilibration process involves transfer of iron from metal to silicate grains, which can proceed by solid-state diffusion if the grains are in contact or by vapor-phase transport if they are not. For $\underline{t}=10 \mathrm{yr}$ and a grain diameter of $10^{-5} \mathrm{~cm}$ (probably 
representative of matrix particles) the diffusion mechanism may be effective to $\sim 630^{\circ} \mathrm{K}$. The limit for vapor phase transport is less certain, but should be of the same order if volatile iron species such as $\mathrm{FeCl}_{2}$ were present.

If this dust is to be transformed into chondrules of the same $\mathrm{Fe}^{2+}$ content, it is obviously necessary that no appreciable reduction take place during remelting. This appears to be feasible. Reduction requires that a sufficient number of $\mathrm{H}_{2}$ molecules from the gas phase impinge on the surface of the molten chondrule. A minimum half-life for $\mathrm{Fe}^{2+}$ reduction can be estimated on the assumption that every impact is effective and that any iron reduced at the surface is instantly replaced by fresh $\mathrm{Fe}^{2+}$ from the interior. At $\mathrm{P}=10^{-4}$ atm and $\mathrm{T}=1200^{\circ} \mathrm{K}$, this minimum half-life is $210 \mathrm{sec}$ for $1 \mathrm{~mm}$ chondrules, of the same order as the freezing time (seconds to minutes). But the actual half-life is likely to be orders of magnitude longer and thus the average degree of reduction will remain slight. Individual chondrules should of course vary, depending on their cooling times, and such variations have in fact been observed in primitive chondrites ( $\mathrm{Fa}{ }_{\sim 0}$ to $\mathrm{Fa}_{90}$ in $03^{\prime} \mathrm{s}$, Van Schmus, 1969; $\mathrm{Fa}_{0.1}$, to $\mathrm{Fa}_{69}$ in $\mathrm{C2}$ 's, Wood, 1967a).

It thus appears that the oxidation state of ordinary chondrites was established directly in the solar nebula, by equilibration of the primary condensate with the gas at $\sim 600^{\circ} \mathrm{K}$.

Enstatite chondrites. - These meteorités are much more strongly reduced. They contain almost iron-free $\mathrm{MgSiO}_{3}$ $\left(\mathrm{Fs}_{0.1-2}\right)$ and minerals such as graphite, FeSi, TiN, and CaS, 
which are stable only under very reducing conditions. It appears that these facts cannot be explained by temperature alone; the gas phase must have been more reducing than cosmic. Larimer (1968b) investigated the thermodynamics in detail and noted that the requisite degree of reducing power could be achieved most simply by a slight increase in $\mathrm{C} / \mathrm{O}$ ratio, from the solar value of 0.6 to about 0.9 or 1.0 . It is well known from stellar spectra and thermodynamic calculations (Suess, 1962; Tsuji, 1964; Dayhoff et al., 1964; Dolan, 1965; Morris and Wyller, 1967) that drastic chemical changes take place when the C/O ratio in a hot cosmic gas approaches unity. The bulk of the oxygen is tied up as $\mathrm{CO}$ and metal oxides, while $\mathrm{H}_{2} \mathrm{O}$ virtually disappears. Since the reducing power of the gas depends on the $\mathrm{H}_{2} / \mathrm{H}_{2} \mathrm{O}$ ratio, various reduced species become prominent. Larimer suggested that the increased $\mathrm{C} / \mathrm{O}$ ratio might be achieved by a slight local enrichment of dust relative to gas, if the dust contained some carbon. Direct condensation of carbon from a solar gas (as graphite or a solid solution in metallic iron) requires rather specialized, though not impossible conditions (Urey, 1953; Eck et al., 1966). Yet the high C/O ratio would have to persist from $\sim 1000^{\circ} \mathrm{K}$ (where silicates otherwise begin to take up significant amounts of $\mathrm{Fe}^{2+}$ ) to $600-700^{\circ} \mathrm{K}$ (temperature of metal-silicate fractionation and chondrule formation). It is not clear that prolonged survival of large, compositionally peculiar regions in the solar nebula is in fact plausible.

Alternative models for the enstatite chondrites have been proposed, involving either reduction of carbon-rich dust in the parent body (Ringwood, 1966) or condensation from a 
cosmic gas supersaturated in Fe vapor at pressures greater than $10^{-2}$ atm (Blander, 1970). All of these models need to be explored further.

Oxidation State During Metal-Silicate Fractionation. Conditions during this fractionation can be estimated from a plot of $\mathrm{Ni} / \mathrm{Mg}$ vs $\mathrm{Fe} / \mathrm{Mg}$ for a group of cogenetic meteorites. The slope gives $\mathrm{Ni} / \mathrm{Fe}$ in metal and the intercept,. $\mathrm{Fe} / \mathrm{Mg}$ in silicate during fractionation. The latter ratio can of course be related to temperature.

Larimer and Anders (1970) have determined these quantities for $\mathrm{O}, \mathrm{E}$, and $\mathrm{C}$ chondrites, on the assumption that all members of each class are cogenetic. The $\mathrm{Fe}^{2+} / \mathrm{Mg}^{2+}$ ratio for $\mathrm{O}$ chondrites is $0.14 \pm 0.02$, corresponding to $\mathrm{T} \approx 700 \pm 15^{\circ} \mathrm{K}$. The $\mathrm{Fe}^{2+} / \mathrm{Mg}^{2+}$. ratio of 0.14 is slightly lower than the present value, suggesting that the fractionation happened shortly before the final stage of oxidation. The ratios for $\mathrm{E}$ and $\mathrm{C}$ chondrites $(0.00 \pm 0.07$ and $0.14 \pm 0.08$ ) have larger errors and hence cannot be used for meaningful temperature estimates.

Organic Matter.

Carbonaceous chondrites contain up to $4 \%$ carbon. Most of it is in the form of an insoluble, aromatic polymer somewhat similar to coal or to humic acid in soils. The remainder consists of $\mathrm{Mg}, \mathrm{Fe}$, and $\mathrm{Ca}$ carbonates and a variety of organic compounds. Ordinary chondrites contain smaller amounts of carbon $(0.01 \%$ to $2 \%$ ) in an ill-defined chemical form, presumably again an aromatic 
polymer (Hayes and Biemann, 1968).

The nature and origin of meteoritic organic matter has been reviewed by Hayes (1967), Vdovykin (1967), and Levin (1969). From the standpoint of the present review, the principal question is whether the organic matter represents a primary condensate from the solar nebula or a secondary product.

Urey (1953) investigated the thermodynamics of carbon condensation from the solar nebula, and showed that simple, non-volatile substances (graphite, $\mathrm{Fe}_{3} \mathrm{C}$ ) could condense only under very specialized and somewhat improbable conditions. At moderate temperatures $\left(<500-600^{\circ} \mathrm{K}\right.$ at $<10^{-3}$ atm), methane is the dominant form of carbon, but is far too volatile to condense in the inner solar system $\left(\mathrm{T}_{\mathrm{c}}=48^{\circ} \mathrm{K}\right.$ at $\left.10^{-3} \mathrm{~atm}\right)$. Urey therefore suggested that the primary condensate consisted of "complex, tarry carbon compounds" similar to those in carbonaceous chondrites. Such compounds might form as metastable intermediates in the transformation of $\mathrm{CO}$, the stable high-temperature form of $\mathrm{C}$ in the solar nebula, to $\mathrm{CH}_{4}$, the stable low-temperature form.

Much detailed information on the organic compounds in meteorites has subsequently become available. We can therefore try to reconstruct the processes that led to the formation of these compounds, and see what relationship they bear to the primary condensation process.

The study of organic compounds in meteorites has been somewhat hampered by contamination, but the isotopic composition of $\mathrm{H}, \mathrm{S}$, and $\mathrm{C}$ 
shows that the major part of the organic matter is indigenous (Briggs, 1963). Surprisingly, the compound distribution is far from random. A few classes or structural types dominate: for example, straight-chain hydrocarbons are far more abundant than their branched-chain counterparts, although the straightchain configuration is only one of. $10^{3}$ to $10^{5}$ structural possibilities for molecules with 15 to 20 carbon atoms. Apparently some highly selective synthesis process was at work.

A mechanism of the right degree of selectivity is the Fi-scher-Tropsch reaction: hydrogenation of $\mathrm{CO}$ in the presence of an iron or cobalt catalyst. This reaction, which is used industrially, produces mainly straight-chain or slightly branched hydrocarbons of the general formula $\mathrm{C}_{n} \mathrm{H}_{2 \mathrm{n}+2}$, e.g.

$$
10 \mathrm{CO}+21 \mathrm{H}_{2} \rightarrow \mathrm{C}_{10} \mathrm{H}_{22}+10 \mathrm{H}_{2} \mathrm{O}
$$

The hydrocarbon distribution resembles that in meteorites (Figure 3 ) and in certain oil shales and natural gases (S.tudier et al., 1968; Friedel and Sharkey, 1968). When $\mathrm{NH}_{3}$ is present in the gas mixture, various nitrogen compounds are produced, including some of biological significance (adenine, guanine, cytosine; the constituent bases of DNA and RNA), and other structurally similar ones (ammeline, melamine) without such significance (Hayatsu et al., 1968). The same compounds have been found in carbonaceous chondrites (Hayatsu, 1964).

A further argument for the Fischer-Tropsch reaction comes 
from the isotopic differences between carbonate carbon (= bonded to 0 , e.g. $\mathrm{MgCO}_{3}$ ) and organic carbon (= bonded to $\mathrm{H}$, e.g. $\mathrm{C}_{\mathrm{x}} \mathrm{H}_{\mathrm{y}}$ ) in carbonaceous chondrites. Clayton (1963) showed that the carbonate carbon was some 7 to $8 \%$ richer in $\mathrm{C}^{13}$ than the organic carbon (Briggs, 1963). This trend was confirmed by. Krouse and Modzeleski (1970) and Smith and Kaplan (1970). Although fractionations of this magnitude are theoretically possible under equilibrium conditions at very low temperatures $\left(\leq 0^{\circ} \mathrm{C}\right)$, they are not observed in nature. Urey (1967) therefore proposed that the two types of carbon came from two unrelated reservoirs. It turns out, however, that the Fischer-Tropsch reaction gives an isotopic fractionation of just the right sign and magnitude at $400^{\circ} \mathrm{K}$ (but not $500^{\circ} \mathrm{K}$ ), owing to a kinetic isotopic effect (Lancet and Anders, 1970). The temperature of $\sim 400^{\circ} \mathrm{K}$ agrees fairly well with the accretion temperature of $\mathrm{C} 2$ chondrites estimated from their volatile element content.

An alternative mechanism that has frequently been proposed for the prebiotic synthesis of organic compounds on Earth is the Miller-Urey reaction: irradiation of $\mathrm{CH}_{4}, \mathrm{NH}_{3}$, and $\mathrm{H}_{2} \mathrm{O}$ by UV, $\gamma$-rays, etc. (Miller, 1953; see Lemmon, 1970, for a recent review). However, this reaction involves random link-up of free radicals, and therefore lacks the required selectivity. It produces all hydrocarbon isomers in comparable amounts, without preference for straight-chain isomers, and does not yield many 
of the heterocyclic or aromatic compounds found in meteorites. Moreover, the Miller-Urey reaction does not give significant. carbon isotope fractionations.

Although the Fischer-Tropsch reaction seems capable of accounting for much of the evidence, there is as yet no certainty that conditions in the solar nebula were in fact appropriate for this reaction. To be sure, a variety of suitable catalysts (nickel-iron, $\mathrm{Fe}_{3} \mathrm{O}_{4}$, hydrated silicates) were undoubtedly present, and so were at least two of the three reactants $\left(\mathrm{NH}_{3}, \mathrm{H}_{2}\right)$. Problems arise for the third reactant, Co, however. In a cooling solar nebula it should be abundant down to $\sim 600^{\circ} \mathrm{K}$. But below this temperature, it becomes unstable, first with respect to $\mathrm{CH}_{4}$, and only later (at temperatures $100^{\circ}$ to $150^{\circ}$ 'Iower) with respect to higher hydrocarbons. Thus, if equilibrium were maintained, most of the $\mathrm{CO}$ would be converted to $\mathrm{CH}_{4}$ before formation of heavier hydrocarbons became possible.

In order to resolve this difficulty, Lancet and Anders (1970) postulated that the hydrogenation of $\mathrm{CO}$ might have been very sluggish until $400^{\circ} \mathrm{K}$, when magnetite began to form. At that temperature, both $\mathrm{CH}_{4}$ and heavier hydrocarbons are thermodynamically possible products; the latter actually form more readily for mechanistic reasons. In support of this suggestion they noted that significant amounts of organic compounds are found only in meteorites containing magnetite.

The survival of any heavy hydrocarbons formed also presents problems. These compounds are unstable with respect to $\mathrm{CH}_{4}$ in 
the presence of excess $\mathrm{H}_{2}$. Studier et al. (1968) have shown that this reaction does not proceed to a perceptible degree during several days at $500^{\circ} \mathrm{K}$ and $\mathrm{P}=10 \mathrm{~atm}$. It is not known, however, whether this is sufficient to ensure survival of hydrocarbons at the lower temperatures, lower pressures, and longer times characteristic of the solar nebula.

Likewise, the reaction has not yet been carried out at the high $\mathrm{H}_{2} / \mathrm{CO}$ ratios $\left(\sim 10^{3}\right)$ and low pressures $\left(\leq 10^{-3} \mathrm{~atm}\right)$ appropriate to the solar nebula, because the carbon content of such a system would be too small for present analytical techniques. of the two variables, pressure seems to be the more critical one. Studier et al. (1968) were able to synthesize hydrocarbons at $\mathrm{H}_{2} / \mathrm{CO}=500$ and $\mathrm{p}=10 \mathrm{~atm}$, but saw no detectable reaction in gas mixtures of lower $\mathrm{H}_{2}$ /CO ratio during several days at $10^{-2}$ or $10^{-3} \mathrm{~atm}$.

Another unsolved problem is the origin of the aromatic polymer. Calculations by Dayhoff et al. (1964) show that aromatic hydrocarbons of high molecular weight might form metastably in systems of low H/C ratio, and this has been confirmed experimentally by Eck et al. (1966). A similar process seems to be involved in the transformation of terrestrial plant remains to coal, and might also occur if the hydrocarbons first formed were reheated in the meteorite parent body after accretion. Some features of the hydrocarbon distribution in meteorites actually seem to call for such reheating (studier 
et al., 1968). However, no material resembling the meteoritic polymer has yet been synthesized in the laboratory.

Summarizing the situation, we can thus state that the Fischer-Tropsch reaction (perhaps augmented by radiation chemistry and reheating) seems to be a likely mechanism for production of the organic compounds in meteorites. Whether this reaction is indeed the primary condensation process sought is less certain. One cannot yet rule out the possibility that the primary condensate was made by some other process (Miller-Urey?), and transformed to Fischer-Tropsch material by secondary reactions in the meteorite parent bodies. Such transformations are in fact observed on earth. The hydrocarbon distribution in some. crude oils, coals, and oil shales is strikingly similar to a Fischer-Tropsch distribution (Figure 3) although these hydrocarbons are obviously made by subterranean degradation of biological material (Friedel and Sharkey, 1963, 1968). Apparently the Fischer-Tropsch pathway is kinetically favored over competing mechanisms in a wide range of conditions. Thus the FischerTropsch compounds in meteorites may be of secondary origin. This problem may soon be resolved by radio astronomers. The organic molecules of growing complexity discovered in interstellar clouds (Palmer and Zuckerman, 1971) seem to require formation in an environment far denser than the cloud itself, i.e. stellar envelopes or "solar nebulae" (Herbig, 1970). These compounds almost certainly were made by the "primary" process of 
carbon condensation. As the list of positive (and negative!) identifications grows longer, it may provide a decisive clue to the nature of the primary process.

\section{Primordial Noble Gases.}

Some meteorites contain remarkably large amounts of noble gases whose isotopic composition. clearly rules out a radiogenic or cosmogenic origin. Such gases have been called "primordial" or "trapped" (Gerling and Levskii, 1956; Zähringer, 1962; Suess et al., 1964; see Pepin and Signer, 1965, for a review). It has gradually become apparent that there exist two varieties of primordial gas. The first, called "solar", contains the noble gases in nearly solar proportions, and is characterized by He and Ne relatively rich in the light isotope: $\mathrm{He}^{3} / \mathrm{He}^{4}=(3.79 \pm 0.40) \times 10^{-4} ; \mathrm{Ne}^{20} / \mathrm{Ne}^{22}=12.5 \pm 0.2$ (Jeffery and Anders, 1970; Black and Pepin, 1969). Solar gas is found sporadically in meteorites of all classes, is always associated with shock and brecciation, and seems to represent trapped solar wind particles (Wänke, 1965). Some authors have proposed that the trapping took place before accretion of the meteorite parent bodies (Pellas et al., 1969; Lal et al., 1969), but the discovery of a similar gas component in lunar soil and breccias suggests that the implantation is an ongoing process in the solar system.

The second, "planetary" component seems to be of much 
more ancient origin. It is disproportionally enriched in the heavier noble gases (not unlike the Earth's atmosphere), and contains lesser amounts of the light isotopes of He and Ne: $\mathrm{He}^{3} / \mathrm{He}^{4}=(1.43 \pm 0.40) \times 10^{-4} ; \mathrm{Ne}^{20} / \mathrm{Ne}^{22}=8.2 \pm 0.4$. It is found only in "primitive" meteorites, e.g. chondrites and ureilites. [The latter, though classified as achondrites, are the least differentiated members of that class. Their high $\mathrm{C}$ content and $0^{18} / 0^{16}$ ratio links them to the carbonaceous chondrites, and some authors believe that they are derived from them by a simple alteration process (Anders, 1964; Vdovykin, 1970)].

There is evidence for several additional types of neon, with $\mathrm{Ne}^{20} / \mathrm{Ne}^{22} \leq 3.4,11.25 \pm 0.25$, and 214 (Black and Pepin, 1969; Black, 1971). The first two are always associated with planetary neon, but the second is not quite firmly established: it may be a mixture of the 8.2 and 12.5 components. The third component seems to be associated with solar gas, but its reality is not yet settled.

We shall be concerned only with the planetary gas, as it alone seems to date from the nebular stage. Three properties need to be explained: amounts, elemental ratios, and isotopic ratios.

The amounts of planetary gas show a most remarkable correlation with petrologic type, among both the ordinary and carbonaceous chondrites (Zähringer, 1966; Marti, 1967; Mazor et al, 1970). Absolute abundances of $\mathrm{Ar}, \mathrm{Kr}$, Xe rise by three orders of magnitude from 06 to $\mathrm{Cl}$ chondrites or ureilites. (He and Ne show a 
different behavior: they are found only in $\mathrm{Cl}, \mathrm{C} 2$ 's and a few O3's). Elemental ratios of the heavier gases ( $\mathrm{Ar} / \mathrm{Kr}, \mathrm{Ar} / \mathrm{Xe}$ ) remain constant within a factor $\leq 6$ over the entire range.

A rather common view is that planetary gases reflect some kind of solubility equilibrium between nebula and solid phase, perhaps modified by adsorption effects. The equilibrium solubility of these gases may be expected to follow Henry's law, the amount of dissolved gas at a given temperature being proportional to its partial pressure. Unfortunately there exist no published data on equilibrium solubility of noble gases in meteoritic minerals at the pertinent temperatures $(\sim 300$ to $600^{\circ} \mathrm{K}$; see above). Kirsten (1968) has measured solubilities in enstatite at $1773^{\circ} \mathrm{K}$, near its freezing point. The distribution coefficient for Ar, for example, was $2 \times 10^{-5} \mathrm{~cm}^{3} \mathrm{STP} / \mathrm{g}$ atm. In order to account for the amounts of planetary Ar in 05,6 chondrites, the distribution coefficient at lower temperatures would have to be some $10^{5 \pm 2}$ times greater (if $P_{t}=10^{-4 \pm 2}$ atm.)

The only pertinent experimental data are some unpublished measurements by M.S.Lancet (quoted by Jeffery and Anders, 1970). The distribution coefficient of $\mathrm{Ar}$ in magnetite is about 1 cc STP/g atm at $500^{\circ} \mathrm{K}$. This is some $5 \times 10^{4}$ times higher than Kirsten's value for enstatite at $1773^{\circ} \mathrm{K}$, and only slightly less than the value required to account for the $\mathrm{Ar}^{36}$ content of 05,6 chondrites. Solubilities for He and Ne are markedly lower, so that magnetite equilibrating with "solar" noble gases should 
absorb them in approximately planetary proportions.

The question is far from settled, however. No solubility data are available for $\mathrm{Kr}$ and $\mathrm{Xe}$, or for meteoritic minerals other than magnetite. It is not at all certain.that these solubilities will be of the right order to account for the evidence. Xenon, in particular, is a problem. The observed amount of Xe in C3 chondrites, for example, requires a distribution coefficient of $-10^{5 \pm 2} \mathrm{~cm}^{3} \mathrm{STP} / \mathrm{g}$ atm, corresponding to a number density in the solid some $3 \times 10^{5 \pm 2}$ higher than in the gas. This implies a rather strong bond between $\mathrm{Xe}$ and the host lattice, corresponding to a heat of solution of about -20 to $-25 \mathrm{kcal} / \mathrm{mole}$. Perhaps adsorption on a growing crystal was involved as a first step. The density of atoms in an adsorbed layer can approach that in a liquid, and even if only a fraction of the adsorbed atoms are trapped in the growing crystal, quite high gas concentrations can result.

An interesting alternative has been proposed by Jokipii (1964):' enrichment of the heavier gases by ambipolar diffusion. In a partially ionized solar nebula, the solar magnetic field would retard ions relative to neutral atoms. Thus the heavier noble gases, with their iower ionization potentials, would be preferentially retained in the inner solar system. Calculated enrichment factors indeed agree rather well with terrestrial atmospheric abundances. This process can also lead to highly efficient trapping of the retained gases, if the ions are 
accelerated and implanted in solid grains.

The isotopic differences between solar and planetary gas have been the subject of much speculation (Pepin and Signer, 1965; Black and Pepin, 1969; Mazor et al., 1970; Black, 1971). Some of the obvious possibilities, such as mass fractionation by gravitational escape (Krummenacher et al., 1962) or diffusion from a solid lattice (Zähringer, 1962) seem rather unlikely, because the elemental and isotopic ratios do not show the expected correlations (Pepin, 1967; Jeffery and Anders, 1970). The existence of a neon component with $\mathrm{Ne}^{20} / \mathrm{Ne}^{22}<3.5$.(Black and Pepin, 1969) is a particularly strong argument against these models, because production of this component from solar neon with $\mathrm{Ne}^{20} / \mathrm{Ne}^{22}=12.5$ requires an implausibly high fractionation factor, $10^{-12}$.

No wholly satisfactory explanation is yet available. The most plausible mechanism is production of $2.6 \mathrm{yr} \mathrm{Na}^{22}$ in meteoritic silicatés by a charged-particle irradiation in the solar nebula, followed by in situ decay to $\mathrm{Ne}^{22}$. The amount of $\mathrm{Na}^{22}$ produced, and hence the final $\mathrm{Ne}^{20} / \mathrm{Ne}^{22}$ ratio, might vary with the composition of the mineral (Jeffery and Anders, 1970). The variations in $\mathrm{He}^{3} / \mathrm{He}^{4}$, on the other hand, might represent a secular increase in the $\mathrm{He}^{3}$ abundance at the solar surface (E. Schatzmann, private communication quoted by Eberhardt et al., 1970). The ratio may have changed from 
$\sim 1.4 \times 10^{-4}$ about $4.6 \mathrm{AE}$ ago to $\sim 4 \times 10^{-4}$ in recent times. [The "recent" ratio is not well-defined; variations were predicted owing to differential acceleration of $\mathrm{He}^{3}$ and $\mathrm{He}^{4}$ (Geiss et al., 1970a) and have been confirmed by measurements on Apollo 11,12 lunar soils and Al-foil solar-wind collectors (Geiss et al., $1970 \mathrm{~b})]$.

\section{CHRONOLOGY OF THE SOLAR NEBULA}

It has been clear for more than a decade that the active period of planet formation lasted no more than a few hundred million years--a few percent of the age of the solar system (Urey, 1957). The obvious challenge to meteoriticists was to determine the length of this interval with greater accuracy, and to resolve individual events within this interval. At first, all such efforts were based on "extinct" radionuclides with half-lives of $10^{7}$ to $10^{8} \mathrm{yr}$, e.g. $16 \mathrm{Myr} \mathrm{I}^{129}$ and $82 \mathrm{Myr}$ $\mathrm{Pu}^{244}$ (Reynolds, 1968; Hohenberg et al., 1967). But more recently, some spectacular advances were made in the $\mathrm{Rb}^{87}-\mathrm{Sr}^{87}$ dating method (Papanastassiou and Wasserburg, 1969). In spite of the long half-life of $\mathrm{Rb}^{87}$ (47 AE), improved mass spectrometric techniques now permit resolution of time differences as small as \pm 2 Myr.

The picture still is quite fragmentary, owing to the lack of a common reference point. All of the methods used measure time intervals between two events, but the events themselves differ from method to method. 
Rubidium-87. - Seven eucrites (Ca-rich achondrites of very low $R b$ content) fall on a well-defined isochron, the maximum deviation being $6 \times 10^{-5}$. This implies that if these meteorites were derived from material with chondritic $\mathrm{Rb} / \mathrm{Sr}$ ratio (0.25), they must have formed within $\leqslant 4$ Myr of each other (Papanastassiou and Wasserburg, 1969).

This result would be trivial if all these meteorites came from a single lava flow. However, this is rather unlikely. Two of the seven meteorites (Stannern and Moore County) differ from the others in composition or texture. Moreover, the radiaticn ages of these meteorites suggest that they originated. in at least 4 and perhaps 7 separate impacts (Heymann et al., 1968). Thus it seems that the 4 Myr isochronism applies to an event of more than local scale. It is interesting in.this connection:that at least one asteroid, Vesta, has a reflection spectrum 'suggestive of a eucritic composition (McCord et al., 1970).

The $\mathrm{Rb} / \mathrm{Sr}$ method has also provided an estimate for the duration of metamorphic heating in chondrite parent bodies. An analysis of the H 6 chondrite Guareña showed that it had a higher $\mathrm{Sr}^{87} / \mathrm{Sr}^{86}$ ratio than the eucrites when its minerals ceased to exchange $\mathrm{Rb}$ and $\mathrm{Sr}$ (Wasserburg et al., 1969). The time required to evolve Guareña $\mathrm{Sr}$ from eucritic $\mathrm{Sr}$ is $74 \pm 12 \mathrm{Myr}$, and probably reflects the duration of metamorphism in this meteorite. Iodine-129. - In the decade since its inception, the $\mathrm{I}^{129} / \mathrm{Xe}^{129}$ dating method has gone through several stages of 
refinement, as certain pitfalls were recognized andi averted. In principle, this method dates the time when the meteorite began to retain $\mathrm{Xe}^{129}$ from the decay of $\mathrm{I}^{129}$. But the various iodine-bearing sites in the meteorite differ greatly in their retentivity, the more Iabile ones retaining less $\mathrm{Xe}^{129}$ to begin with and being most vulnerable to losses in subsequent reheating events. Manuel et al. (1968) have used data on low-retentivity sites to estimate cooling rates of chondrite parent bodies. The results, 5 to $9^{\circ} \mathrm{C} / \mathrm{My}$, are reasonably consistent with metallographically determined cooling rates, 2 to $10^{\circ} \mathrm{C} / \mathrm{Myr}$ (Wood, $1967 \mathrm{~b}$ ). However, for determining the chronology of the early solar system, data for high-retentivity rates are most pertinent. Podosek (1970) has measured (or reinterpreted) such datá on $\cdot 17$ meteorites. A variety of chondrite classes and petrologic types were represented: $\mathrm{C}(2,4) ; \mathrm{E}(4,5) ; \mathrm{H}(5) ; \mathrm{L}(4,6) ; \mathrm{LL}(3,6) ;$ as wel1 as aubrites, a nakhlite and a silicate inclusion from a hexahedrite. Most of these meteorites began to retain $\mathrm{Xe}^{129}$ within 6 to 8 Myr of each other. Errors were often on the order of 1 Myr or less, and thus at least some of these differences seem to be real.

It is difficult to make generalizations, however, because only a few members of eăch class have been measured thus far. A safe conclusion is that the parent bodies of many meteorite classes cooled to xenon-retention temperatures (1000- $1500^{\circ} \mathrm{K}$ ?) within 6-8 Myr of each other. Since cooling rates must have varied with size of the body, the small spread in cooling times implies an even smaller spread in formation times: a few million years or less. 
Actually, the time scale may have been considerably shorter still. Hanks and Anderson (1969) have shown that the existence of 3.6 AE old rocks on the Earth implies core formation at the very beginning of the Earth's history, in order to allow time for removal of the energy released. This in turn requires a high initial temperature and hence a short accretion time: 0.5 Myx or less. Though this time scale does not necessarily apply to the formation of asteroids and planetesimals, it does strengthen the case for rapid evolution of the inner solar system.

Podosek and Hohenberg (1970) noted that three primitive chondrites: Renazzo (C2), Chainpur (LL3), and Manych (L3) did not give precise isochrons. They suggest that some of the constituents of these meteorites have retained the I-Xe record of an earlier stage, but there are other alternatives. At least one of these meteorites has been severely reheated by shock (Wood, 1967b). This might have redistributed $\mathrm{I}$ and Xe so as to smear out any initial correlations.-

The I-Xe method has not yet been able to establish the relative age of chondrules and matrix. The matrix of Chainpur appears to be $7.4 \mathrm{Myr}$ older than the chondrules; but data on Renazzo suggest an age difference of 16 Myr in the reverse direction. In view of the ambiguities surrounding these two meteorites, the question must be regarded as open.

Aluminum-26. - This nuclide $\left(t_{\frac{1}{2}}=0.74 \mathrm{Myr}\right)$ would be produced in fairly high abundance in nucleosynthetic processes, and has therefore been proposed as a heat source for the melting of asteroids (Urey, 1955; Fish et al., 1960). A slight ( 0.4 to $0.6 \%$ ) enrichment of $\mathrm{Mg}^{26}$ in $\mathrm{Al-rich}$ meteorite phases was 
tentatively attributed by Clarke et al (1970) to $\mathrm{Al}^{26}$, but a later study by Schramm et al. (1970) showed no perceptible enrichment to a $2 \sigma$ upper limit of $50.05 \%$. All meteorites in this study were highly evolved, i.e. achondrites or Type 6 chondrites. This suggests that no detectable amounts of $\mathrm{Al}^{26}$ were present when the feldspar in these meteorites ceased exchanging Mg with other silicate phases, but does not preclude the possibility that significant amounts of $\mathrm{Al}^{26}$ were present several million years earlier.

Superheavy Elements. - Xenon from chondrites is enriched in the heavier isotopes $\left(\mathrm{Xe}^{131}-\mathrm{Xe}^{136}\right)$ in proportions suggestive of heavy-element fission (see Rowe, 1968, for data and references to earlier work). Yet the isotopic ratios do not correspond to the fission spectrum of any known nuclide, and the amounts are far larger than expected from spontaneous fission of $4.51 \mathrm{AE}$ $\mathrm{U}^{238}$ or 82 Myr. $\mathrm{pu}^{244}$.

The abundance of this fission component parallels that of the most volatile elements: $\mathrm{Pb}, \mathrm{Bi}, \mathrm{Tl}$, In, $\mathrm{Hg}, \mathrm{Xe}$, etc., being highest in the most primitive chondrites. Anders and Heymann (1969) therefore suggested that the progenitor of the fission component was a superheavy element with atomic number $\mathrm{Z} 112$ to 119, because these elements (congeners of the Hg-Fr sequence) are the only volatile ones between $\mathrm{Z}=88$ and $\geq 130$. Indeed, an "island of stability" centered on $\mathrm{Z}=114, \mathrm{~A}=298$ has beeǹ predicted from nuclear systematics. (See Seaborg, 1968, for a general review of superheavy elements, and Dakowski, 1969, and Rao, 1970, for a further discussion of the meteorite problem). 
Nucleosynthesis. - The presence in meteorites of extinct radionuclides shows that the last nucleosynthetic event which contributed matter to the solar system occurred no more than a few hundred Myr before the formation of the solar system. The simple picture that all solar-system matter was synthesized in a single event was abandoned long ago. Almost certainly several successive stages were involved; and there have been many attempts to determine the number, duration, and relative importance of such stages. from.the abundances of radioactive nuclides. Early models generally assumed "continuous" nucleosynthesis over a long period of time (10-20 AE), at a constant or slowly declining rate (Fowler and Hoyle, 1960; Kohman, 1961). More recent efforts favor "prompt" synthesis of the major part of the elements at an early stage (Dıcke, 1969; Unsöld, 1969), followed by continuous synthesis and a "last-minute" event just before the formation of the solar system. Hohenberg (1969) has estimated that the three stages contributed $81-89,0-8$, and $11-13 \%$ of the total $\underline{r}$-process material ever produced. Prompt synthesis began 8.0 to $8.8 \mathrm{AE}$ ago, while last-minute synthesis took place 176 to 179 Myr before the onset of $\mathrm{Xe}^{129}$ retention in chondrites. Schramm and Wasserburg (1970) have shown, however, that these estimates are still model-dependent to a considerable extent. The mean age of the elements might indeed be close to Hohenberg's estimate of $8 \mathrm{AE}$, but the time-dependence of the nucleosynthesis function is not well-determined, and thus total times as high as 
200 AE cannot be excluded. The interval between cessation of nucleosynthesis and onset of Xe-retention is better defined, and probably lies between 75 and 250 Myr.

\section{SUMMARY}

Most of the chemical differences among chondrites, involving some 55 elements, can be explained by a small number of fractionatiol processes in a cooling solar nebula.

\section{A. Ordinary Chondrites (2 to 4 a.u.).}

1. An early condensate, containing about $1 / 3$ of the refractory elements ( $\mathrm{Ca}, \mathrm{Al}, \mathrm{Ti}, \mathrm{U}, \mathrm{Th}$, lanthanides, Pt metals, etc.), was lost at $\geq 1300^{\circ} \mathrm{K}$.

2. After condensation of the remaining. material to grains of $10^{-5}-10^{-6} \mathrm{~cm}$, up to $50 \%$ of the nickel-iron was lost. The fractionation seems to have taken place below $1050^{\circ} \mathrm{K}$, perhaps around $700^{\circ} \mathrm{K}$, and may have been based upon the ferromagnetic properties of the metal grains.

3. When the $\mathrm{Fe}^{2+}$ content of the silicates had risen to $20 \%$ by equilibration with the nebular gas, perhaps $75 \%$ of the condensate was remelted to millimeter-sized droplets by local heating events (electric discharges), on a time scale of seconds to minutes. Volatiles were lost from the remelted material.

4. The unremelted, fine-grained material continued to take up volatiles from the nebula ( $\mathrm{Pb}, \mathrm{Bi}, \mathrm{T} 1$, In, etc.) and accreted together with the remelted material. Accretion took place in a 
$100^{\circ}$ interval centered on $510_{-60}^{+80} \mathrm{~K}$, at a pressure of $10^{-4 \pm 2}$ atm. B. Enstatite Chondrites (2 to 4 a.u., perhaps inner fringe of asteroid belt).

1. As above, but loss approached. $50 \%$.

$2 ., 3$. As above, but in a more reducing gas phase $(\mathrm{C} / \mathrm{O} \geq$ 0.9?). No fully satisfactory explanation for the more reducing gas composition is available. A gas-dust fractionation is a possibility.

4. As above. The total pressure may have been higher.

5. As above, but temperature and cooling rate are less we11determined.

C. Carbonaceous Chondrites [outer fringe of asteroid belt, or original source région of comets ( 5 to 40 a.u.?)].

1., 2. These processes seem to have been largely inoperative in the source region of the carbonaceous chondrites. Only a slight metal-silicate fractionation ( $510 \%)$ is evident among members of this group.

3. There is no evidence for remelting in $\mathrm{Cl}^{\prime} \mathrm{s}$ ( $\leq 10 \%$ is possible, though). $\mathrm{C} 2$ 's to $\mathrm{C} 4$ 's show an increasing degree of remelting ( $\$ 40 \%$ to. $\sim 70 \%)$.

4. Accretion seems to have taken place from $\sim 450^{\circ} \mathrm{K}$ to $\sim 300^{\circ} \mathrm{K}$. Hydrated silicates, magnetite, and organic compounds are present in meteorites that accreted below $400^{\circ} \mathrm{K}\left(\mathrm{Cl} / \mathrm{s}, \mathrm{C} 2^{\prime} \mathrm{s}\right.$, some C3's). The pressure may have been slightly lower than that in 
the region of ordinary chondrites, but probably not less. than $\sim 10^{-6}$ atm.

5. Reheating was much less severe than for ordinary chondrites, especially in the case of $\mathrm{Cl}^{\prime} \mathrm{s}$ and $\mathrm{C2}$ 's.

D. Inner Planets (0.4 to 1.5 a.u.).

1. Uncertain, and possibly small. Earth and Moon may be slightly ( $550 \%)$ enriched in refractories.

2. Uncertain, and possibly small. Earth and Venus may be slightly ( $10 \%$ to $\sim 30 \%)$ enriched in Fe. Extreme values of $\mathrm{Fe} / \mathrm{Si}$ in Mercury and Moon may be due to special factors: early condensation of $\mathrm{Fe}$ at 0.4 a.u. and preferential accretion; fractionation of metal between planet and satelite.

3. Remelting may have affected the major part of planetary matter. The depletion of alkalis in the Earth and Moon suggests contents of $\sim 85 \%$ and $\sim 95 \%$ remelted, alkali-free material.

4. Abundance pattern of volatiles in Earth is similar to that in ordinary chondrites. This is consistent with accretion. either at a constant temperature near $500^{\circ} \mathrm{K}$, or at falling temperatures; the last few percent of the accreted material being carbonaceous-chondrite-like. The 100-fold greater depletion of the Moon implies either formation at higher temperatures (600$650^{\circ} \mathrm{K}$ ) or a much smaller content of the volatile-rich, carbonaceouschondrite-like component.

The principal conclusion of this paper is that substantial chemical fractionations took place in the inner solar system. 
These processes were independent of each other, and thus the known meteorite types represent only a limited sampling of the possible range of planetary materials. At least seven degrees of freedom are available for the composition of planetary matter: depletion (or enrichment), of refractories and metal; condensation temperatures and oxidation states of remelted and unremelted material, and proportions of remelted and unremelted material.. Acknowledgments. I am indebted to Prof. Johannes Geiss for his hospitality during my stay at Berne. This work was supported in part by AEC Contract AT(11-1)-382, NASA Grant NGR 14-001-010, and the Kommission für WeItraumforschung der Schweizerischen Naturforschenden Gesellschaft. 


\section{LITERATURE CITECD}

Ahreñs, L. H., yon Michaelis, H., Erlank, A. J., Willis, J. P. 1969. Meteorite Research, ed. P. M. Millman, 166-173..

D. Reidel: Dordrecht. 940 .pp.

Anders, E. 1964. Space Sci. Rev: 3:583:714

Anders, E. 1968. Acc. Chem. Res. 1:289-298

Anders, E. 1970. Sćience 169:1309-1310

Anders, E. 1971. Geochim. Cosmochim. Acta 35, in press

Anders, E., Heymann, D. 1969: Science 164:821-823

Anderson, D. L., Sammis, C., Jordan, T. 1970. Preprint

Arnold, J. R., Suess, H. E. 1969. Ann. Rev. Phys. Chem. 20:293-314 Arrhenius, G., Alfvén, H. 1970. Earth Planet. Sci. Lett., in press Banerjee, S. K. 1967. Nature 216:781

Baschek, B., Garz, T., Holweger, H., Richter, J. 1970. Astron. Astrophys. $4: 229-233$

Black, D. C. 1971. Preprint

Black, D. C., Pepin, R. 0. 1969. Earth Planet. Sci. Lett. 6:395-405

Blander, M. 1970. Geochim. Cosmochim. Acta 34, in press

Blander, M., Abdel-Gawad, M. 1969. Geochim. Cosmochim. Acta $33: 701-716$

Blander, M., Katz, J. L. 1967. Geochim. Cosmochim. Acta 31:1025-1034

Briggs, M. H. 1963. Nature 197:1290

Brown, H. 1950. Ap. J. 111:641-653

Bullen, K. 'E. 1969. Ann. Rev. Astron. Astrophys. 7:177-200

Cameron, A. G. W. 1962. Icarus 1:13-69

Cameron, A. G. W. 1963. Icarus 1:339-342 
Cameron, A. G. W. 1966. Earth Planet. Sci. Lett. 1:93-96

Cameron, A. G. W. 1968. Origin and Distribution of the Elements,

ed. L. H. Ahrens, 125-143. Pergamon, Oxford. 1178 pp.

Cameron, A. G. W. 1969. Meteorite Research, ed. P. M. Millman, 7-15. D. Reidel, Dordrecht $940 \mathrm{pp}$.

Chou, C.-L. Cohen, A. J. 1970. Gallium and Germanium in the Metal Phase of $\mathrm{L}$ and LL-Group Chondrites. Presented at 33 rd Ann. Meet. Meteorit. Soc., Skyland, Va.

Christophe Michel-Lévy, M. 1968. Bull. Soc. Fr. Minéral. Cristallogr. $91: 212-214$

Christophe Michel-Lévy, M. 1969. Meteorite Research, ed. P. M. Miliman, 492-499. D. Reidel, Dordrecht. 940 pp.

Clark, S. P., Turekian, K. K., Grossman, L. 1971. "The Early History of the Earth". To be published in proceedings of a Symposium in Honor of Francis Birch

Clarke, W. B., delaeter, J. R., Schwarcz, H. P., Shane, K. C. 1970. J. Geophys. Res. 75:448-462

Clayton, R. N. 1963. Science 140:192-193

Dakowski, M. 1969. Earth Planet. Sci. Lett. 6:152-154

Dayhoff, M. O., Lippincott, E. R., Eck, R. V. 1964. Science $146: 1461-1464$

Dicke, R. H. 1969. Ap. J. 155: 123-134

Dodd, R. T. 1969. Geochim. Cosmochim. Acta 33:161-203

Dodd, R. T., Van Schmus, W. R., Koffman, D. M. 1967. Geochim. Cosmochim. Acta 31:921-951

Dolan, J. F. 1965. Ap. J. 142:1621-1632

DuFresne, E. R., Anders, E. 1962. Geochim. Cosmochim. Acta 
Eberhardt, P., et al. 1970. Geochim. Cosmochim. Acta Suppl. 1: $1037-1070$

Eck, R. V., Lippincott, E. R., Dayhoff, M. O., Pratt, Y. T. 1966. Science $1.53: 628-633$

Ehmann, W. D., Lovering, J. R. 1967. Geochim. Cosmochim. Acta $31: 357-376$

Fish, R. A., Goles, G. G., Anders, E. 1960. Ap. J. 132:243-258

Fowler, W. A., Hoyle, F. 1960. Ann. Phys. 10:280-302

Friede1, R. A.; Sharkey, A. G., Jr. 1963. Science 139:1203-1205

Friedel, R. A., Sharkey, A. G., Jr. 1968. U.S. Bur. Mines, Rep. Invest. 7122. U. S. Dept. Interior

Ganapathy, R., Keays, R. R., Laul, J. C., Anders, E. 1970.

Geochim. Cosmochim. Acta Suppl. 1:1117-1142

Garz, T., Kock, M. 1969. Astron. Astrophys. 2:274-279

Garz, T., et al. 1969. Nature 223:1254-1255

Garz, T., Richter, J., Holweger, H., Unsöld, A. 1970. Astron. Astrophys. $7: 336-339$

Gast, P. W. 1968. History of the Earth's Crust, ed. R. Phinney, 15-27. Princeton Univ. Press, Princeton. 244 pp.

Geiss, J., Eberhardt, P., Bühler, F., Meister, J., Signer, P. 1970b. J. Geophys. Res. 75:5972-5979

Gerling, E. K., Levskii, L. K. 1956. Dok. Akad. Sci. U.S.S.R. $110: 750-753$

Gilman, R. C. 1969. Ap. J. 155:L185-L187

Goles, G. G. 1969. The Handbook of Geochemistry, I:Chap. 5, 123. Springer, Berlin. 
Hanks, T. C., Anderson, D. L. 1969. Phys. Earth planet. Interiors $2: 19-29$

Harris, P. G., Tozex, D. C. 1967. Nature 215:1449-1451

Hayatsu, R. 1964. Science 146:1291-1293

Hayatsu, R., Studier, M. H., Oda, A., Fuś, K., Anders, E. 1968. Geochim. Cosmochim. Acta 32:175-190

Hayes, J. M. 1967. Geochim. Cosmochim. Acta 31:1395-1440

Hayes, J. M., Biemann, K. 1968. Geochim. Cosmochim. Acta 32 : 239-267

Herbig, G. H. 1969. "Introductory Remarks to Symposium 'Evolution des Etoiles avant leur Sejour sur la Sequence Principale'". Mém. Soc. Sci. Liège $\left[8^{\circ}\right]$, in press.

Herbig, G. H. 1970a. Optical Spectroscopy of Interstellar

Molecules. Presented at meeting of Am. Astron. Soc., Boulder, Colorado

Herbig, G. H. 1970b. Preprint. Contribution from the Lick Observatory, No. 317.

Heymann, D., Mazor, E., Anders, E. 1968. Geochim. Cosmochim. Acta $32: 1241-1268$

Hohenberg, C. M. 1969. Science 166:212-215

Hohenberg, C. M., Munk, M. N., Reynolds, J. H. 1967. J. Geophys. Res. $72: 3139-3177$

Jeffery, P. M., Anders, E. 1970. Geochim. Cosmochim. Acta $34:^{\circ}$ $1175-1198$

Jokipii, J. R. 1964. Icarus 3:248-252

Keays, R. R., Ganapathy, R., Anders, E. 1971. Geochim. Cosmochim. Acta 35, in press

Keil, K., Huss, G. I, Wiik, H. B. 1969. Meteorite Research, ed.

P. M. Millman, 217. D. Reidel, Dordrecht. 940 pp.

Kirsten, T. 1968. J. Geophys. Res. 73:2807-2810

Kohman, T. P. 1961. J. Chem. Educ. 38:73-82 
Krouse, H. R., Modzeleski, V. E. 1970. Geochim. Cosmochim. Acta $34: 459-474$

Krummenacher, D., Merrihue, C. M., Pepin, R. O., Reynolds, J. H. 1962. Geochim. Cosmochim. Acta 26:231-240

Lal, D., Rajan, R. S. 1969. Nature 223:269-271

Lancet, M. S., Anders, E. 1970. Science 170:980-982

Larimer, J. W. 1967. Geochim. Cosmochim. Acta 31:1215-1238

Larimer, J. W. 1968a. Geochim. Cosmochim. Acta 32:1187-1207

Larimer, J. W. 1968b. Geochim. Cosmochim. Acta 32:965-982

Larimex, J. W. 1970. Presented at Conf. Orig. Evol. Planets,

Calif. Inst. Tech., Jet Propulsion Lab, Pasadena, California

Larimer, J. W. 1971. Geochim. Cosmochim. Acta 35, in press

Larimer, J. W., Anders, E. 1967. Geochim. Cosmochim. Acta 31:

$1239-1270$

Larimer, J. W., Anders, E. 1970. Geochim. Cosmochim. Acta 34: $367-388$

Laul, J. C., Keays, R. R., Ganapathy, R., Anders, E. 1970. Earth Planet. Sci. Lett. 9:211-215

Lemmon, R. M. 1970. Chem. Revs. 70:95-109

Levin, B. J. 1957. Mém. Soc. Sci. Liège IV Ser. 18:186-197

Levin, B. J. 1963. Mém. Soc. Sci. Liège V Ser. 7:39-46

Levin, B. J. 1969. Russ. Chem. Rev. 38:65-78

Lord, H. C., III. 1965. Icarus 4:279-288

Low, F. J. 1969. Science 164:501-505

Low, F. J., Smith, B. J. 1966. Nature 212:675-676

Manuel, O. K., Alexander, E. C., Jr., Roach, D. V., Ganapathy,

R. 1968. Icarus 9:291-304

Marti, K. 1967. Earth Planet. Sci. Lett. 2:193-196 
Marvin, U. B., Wood, J.A., Dickey, J. S., Jr. 1970. Earth planet. Sci. Lett. $7: 346-350$

Mazor, E., Heymann, D., Anders,; E. 1970. Geochim. Cosmochim. Acta $34: 781-824$

McCord, T. B., Adams, J. B., Johnson, T. V. 1970. Science 168:

1445-1447

Miller, S. I. 1953. Science 117:528-529

Morris, S., Wyller, A. A. 1967. Ap. J. 150:877-907

Mueller, O., Baedecker, p., Wasson, I. 1971. Geochim. Cosmochim. Acta 35, in press

Noddack, I., Noddack, W. 1930. Naturwiss. 18:758-764

Palmer, P., Zuckerman, B. 1971. Ann. Rev. Astron. Astrophys.

9, in press

Papanastassiou, D. A:, Wasserburg, G. J. 1969. Earth Planet. Sci. Lett. $5: 361-376$

Pellas, P., Poupeau, G., Lorin, J. C., Reeves, H., Audouze, J. 1969. Nature $223: 272-274$

Pepin, R. O. 1967. Earth Planet. Sci. Lett. 2:13-18

Pepin, R. O., Signer, P. 1965. Science 149:253-265

Podosek, F. A. 1970. Geochim. Cosmochim. Acta 34:341-366

Podosek, F. A., Hohenberg, C. M. 1970. Earth Planet. Sci. Lett. $8: 443-447$.

Rao, M. N. 1970. Nucl. Phys. \$140:69-73

Reed, G. W., Jr., Jovanovic, S. 1967. J. Geophys. Res. 72 : 2219-2228 
Reynolds, J. H. 1968: Origin and Distribution of the Elements, ed. L. H. Ahrens, 367-377. Pergamon, Oxford, 1178 pp.

Ringwood, A. E. 1959. Geochim. Cosmochim. Acta 15:257-283

Ringwood, A. E. 1966. Geochim. Cosmochim. Acta 30:41-104

Ringwood, A. E., Essene, E. 1970. Science 167:607-610

Rowe, M. W. 1968. Geochim. Cosmochim. Acta 32:1317-1326

Schmitt, R. A., Smith, R. H., Goles, G. G. 1965. J. Geophys. Res. $70: 2419-2444$

Schramm, D. N., Tera, F., Wasserburg, G. J. 1970. Earth Planet. Sci. Lett., in press

Schramm, D. N., Wasserburg, G. J. 1970. Ap. J. 162:57-69

Seaborg, G.T. 1968. Ann. Rev. Nucl. Sci. 18:53-152

Singer, S. F., Bandermann, L. W. 1970. Science 170:438-439

Smith, J.. W., Kaplan, I. R. 197.0. Science 167:1367-1370

Studier, M., H., Hayatsu, R., Anders, E. 1968. Geochim. Cosmochim. Acta: $32: 151-174$

Suess, H. E. 1962. J. Geophys. Res. 67:2029-2034

Suess, H. E. 1963. Origin of the Solar System, eds. R. Jastrow and A. G. W. Cameron, 143-146. Academic Press, New York

Suess, H. E. 1964. Isotopic and Cosmic Chemistry, eds. H. Craig, S. L. Miller and.G. :J. Wasserburg, 385-400. North-Holland, Amsterdam

Suess, H. E. 1965. Ann. Rev. Astron. Astrophys. 3:217-234

Suess, H. E., Wänke, H., Wlotzka, F. 1964. Geochim. Cosmochim. Acta $28: 595-607$

Tandon, S. N., Wasson, J. T. 1968. Geochim. Cosmochim. Acta 32: $1087-1109$

Tsuji, T. 1964. Ann. Tokyo Astron. Obs., Univ. Tokyo, 2nd Ser., Vol. IX, No. 1, Mitaka, Tokyo 
Turekian, K. K., Clark, S. P., Jr. 1969. Earth Planet. Sci.

Lett. $6: 346-348$

Unsöld, A. O. J. 1969. Science 163:1015-1025

Urey, H. C. 1952a.'Geochim. Cosmochim. Acta 2:269-282

Urey, H. C. 1952b. The Planets. Yale Univ. Press, New Haven. 245 pp.

Urey, H. C. 1953. Plenary Lectures, XIIIth Intl. Cong. of pure and Appl. Chem., London, 1953, 188-214

Urey, H. C. 1954. Ap. J., Suppl. 1 [6]:147-173

Urey, H. C. 1955. Proc. Nat. Acad. U.S. 41:127

Urey, H. C. 1956. Ap. J. 124:623-637

Urey, H. C. 1957. Progr. Phys. Chem. Earth 2:46

Urey, H. C. 1961. J. Geophys. Res. 66:1988-1991

Urey, H. C. 1964. Revs. Geophys. 2:1-34

Urey, H. C. 1967. Quart. J. Roy. Astron. Soc., London 8:23-47

Urey, H. C., Craig, H. 1953. Geochim. Cosmochim. Acta 4:36-82

Van Schmus, W. R. 1969. Earth Sci. Rev. 5:145-184

Van Schmus, W. R., Wood, J. A. 1967. Geochim. Cosmochim. Acta

$31: 747-765$

Vdovykin, G. P. 1967. Carbon Matter of Meteorites Corganic

Compounds, Diamonds; Graphite). Nauka Publishing Office, Moscow. $271 \mathrm{pp}$.

Vdovykin, G. P. 1970. Space Sci. Revs. 10:483-510

Wänke, H. 1965. Z. Naturforsch. 20a:946-949

Wasserburg, G. J., Papanastassiou, D. A., Sanz, H. G. 1969.

Earth Planet. Sci. Lett. $7: 33-43$

Whipple, F. L. 1966. Science 153:54-56 
Wood, J. A. 1958. Smithsonian Inst. Astrophys. Obs. Technical

Rpt. No. 10. (ASTIA Doc. No. AD 158364)

Wood, J. A. 1962a. Geochim. Cosmochim. Acta 26:739-749

Wood, J. A. 1962b. Nature 194:127-130

Wood, J. A. 1963. Icarus 2:152-180

Wood, J. A. 1967a. Geochim. Cosmochim. Acta 31:2095-2108

Wood, J. A. 1967b. Icarus $6: 1-49$

YavneI, A. A. 1970. Geokhimiya, 228-242

Zähringer, J. 1962. Z. Naturforsch. 17a:460-471

Zähringer, J. 1966. Earth planet. Sci. Lett. 1:379-382 
TABLE 1. CLASSIFICATION OF CHONDRITES ${ }^{a}$

\begin{tabular}{|c|c|c|c|c|c|c|}
\hline Chemical Group & $\begin{array}{c}\text { Petrol. } \\
\text { Types }\end{array}$ & $\frac{\mathrm{Fe}_{\text {metal }}}{\mathrm{Fe}_{\text {total }}}$ & $\mathrm{Fe} / \mathrm{Si}$ & $\mathrm{Mg} / \mathrm{Si}$ & $\frac{\mathrm{Fe}^{2+}}{\left(\mathrm{Fe}^{2+}+\mathrm{Mg}^{2+}\right)}$ & $\begin{array}{l}\text { Known } \\
\text { Falls }\end{array}$ \\
\hline enstatite & $3-6$ & $0.80 \pm 0.10$ & $0.83 \pm 0.32$ & $0.79 \pm 0.06$ & $0-2 \%$ & 17 \\
\hline $\mathbf{H}$ & $3-6$ & $0.63 \pm 0.07$ & $0.83 \pm 0.08$ & $0.96 \pm 0.03$ & $16-20 \%$ & 413 \\
\hline ordinary ("O") & $3-6$ & $0.33 \pm 0.07$ & $0.59 \pm 0.05$ & $0.94 \pm 0.03$ & $22-26 \%$ & 504 \\
\hline LL & $3-6$ & $0.08 \pm 0.07$ & $0.53 \pm 0.03$ & $0.94 \pm 0.03$ & $27-31 \%$ & 49 \\
\hline carbonaceous & $1-4$ & low & $0.83 \pm 0.08$ & $1.05 \pm 0.03$ & $33 \%$ & 36 \\
\hline
\end{tabular}

a After Van Schmus (1969)

$\mathrm{b}$ Atom percentage of $\mathrm{Fe}^{2+}$ in principal ferromagnesian silicate $\left[(\mathrm{Mg}, \mathrm{Fe}) \mathrm{SiO}_{3}\right.$ in enstatite chondrites and $(\mathrm{Mg}, \mathrm{Fe})_{2} \mathrm{SiO}_{4}$ in all others]. Values given refer to petrologic types 4 to 6; those in types 1 to 3 cover a wider range and generally extend down to 0 .

C The symbols $\mathrm{H}, \mathrm{L}$, and LL refer to total iron content, and stand for "high", "low", and "low-low", respectively. We shall find it convenient to use the collective symbol "O" for these classes." 
TABLE 2. Accretion Temperatures of L-Chondrites From Content of Volatile Metals ${ }^{a}$ (Total Pressure $=10^{-4}$ atm)

\begin{tabular}{lcccc} 
& & \multicolumn{3}{c}{ Temperature $\left({ }^{\circ} \mathrm{K}\right)$} \\
Meteorite & Class & Bi & T1 & In \\
\hline Mezö-Madaras & L3 & - & 464 & 464 \\
Krymka & L3 & 483 & - & 474 \\
Khohar & L3 & 490 & 480 & 479 \\
Tennasilm & L4 & $\underline{469}$ & $\underline{466}$ & 501 \\
Barratta & L4 & 489 & 499 & 486 \\
Fukutomi & L4 & 505 & 504 & 491 \\
Goodland & L4 & 510 & 498 & - \\
Homestead & L5 & $\underline{508}$ & $\underline{498}$ & 529 \\
Farmington & L5 & 521 & $\underline{500}$ & 534 \\
Modoc & L6 & 554 & - & 533 \\
Bruderheim & L6 & 556 & 551 & 548 \\
\hline & & & & \\
\hline
\end{tabular}

a

From Keays et al. (1971)

b Italicized values disagree with In-based temperatures and are deemed less reliable. Perhaps they reflect unforeseen complexities in the condensation behavior of $\mathrm{Bi}$ and $\mathrm{T} I$. 


\section{Figure Captions}

Figure 1. Condensation sequence of a gas of cosmic composition (Larimer, 1967; Anders, 1968, with minor revisions). Slowcooling sequence assumes diffusional equilibrium between . grain surfaces and interiors, with formation of solid solutions, while fast-cooling sequence corresponds to deposition of pure elements and compounds, without interdiffusion. Shaded areas represent condensation or chemical transformation of major constituents. The formation range of hydrated silicates is poorly known.

Figure 2. Volatile elements are underabundant in C2 and C3 chondrites relative to $\mathrm{Cl}^{\prime} \mathrm{s}$, by nearly constant factors. Even for the strongly depleted elements $\mathrm{C}$ to $\mathrm{Kr}$, relative abundances stand in approximately the same ratio, 1:0.6:0.3. Bashed line: mean abundances in ordinary chondrites. (Data from Larimer and Anders, 1967; Anders, 1968, with minor revisions.)

Figure 3. Gas chromatogram of hydrocarbons in the range $\mathrm{C}_{15}$ to $\mathrm{C}_{16}$ (unpublished work by M. H. Studier and R. Hayatsu). Synthetic Product: from $\mathrm{CO}$ and $\mathrm{D}_{2}$ by a Fischer-Tropsch reaction; Nonesuch Shale: terrestrial oil shale, about 1.1 AE old (hydrocarbon fraction courtesy W. G. Meinschein); Murray Meteorite: C2 chondrite. Only 6 of the $\sim 10^{4}$ isomeric hydrocarbons with 16 $C$ atoms are present in appreciable abundance; 5 of these (underlined) are common to all three samples. Identifications were confirmed by mass spectrometry. (Me = methyl; B.P. = branched paraffin) 


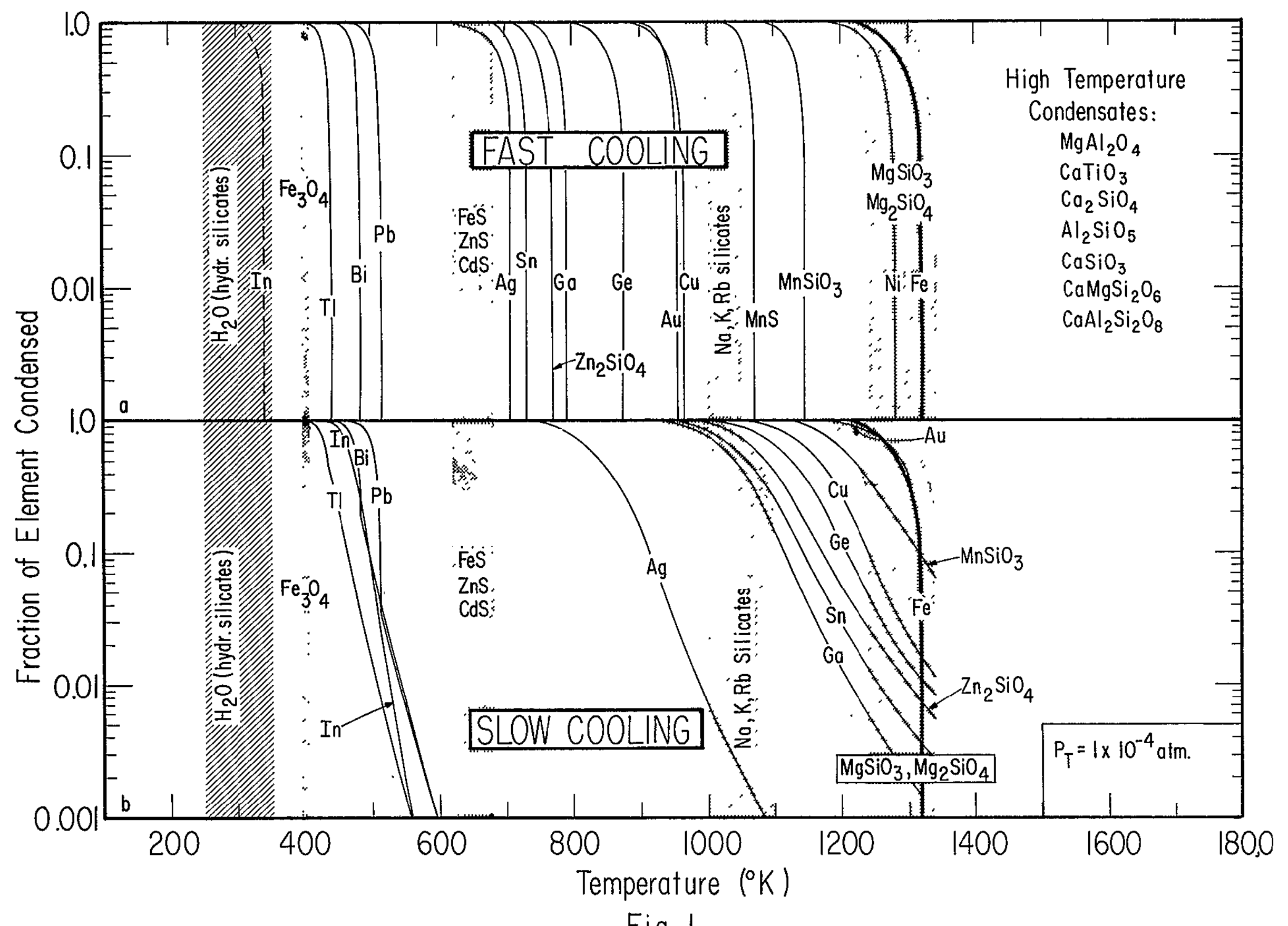

Fig. I 


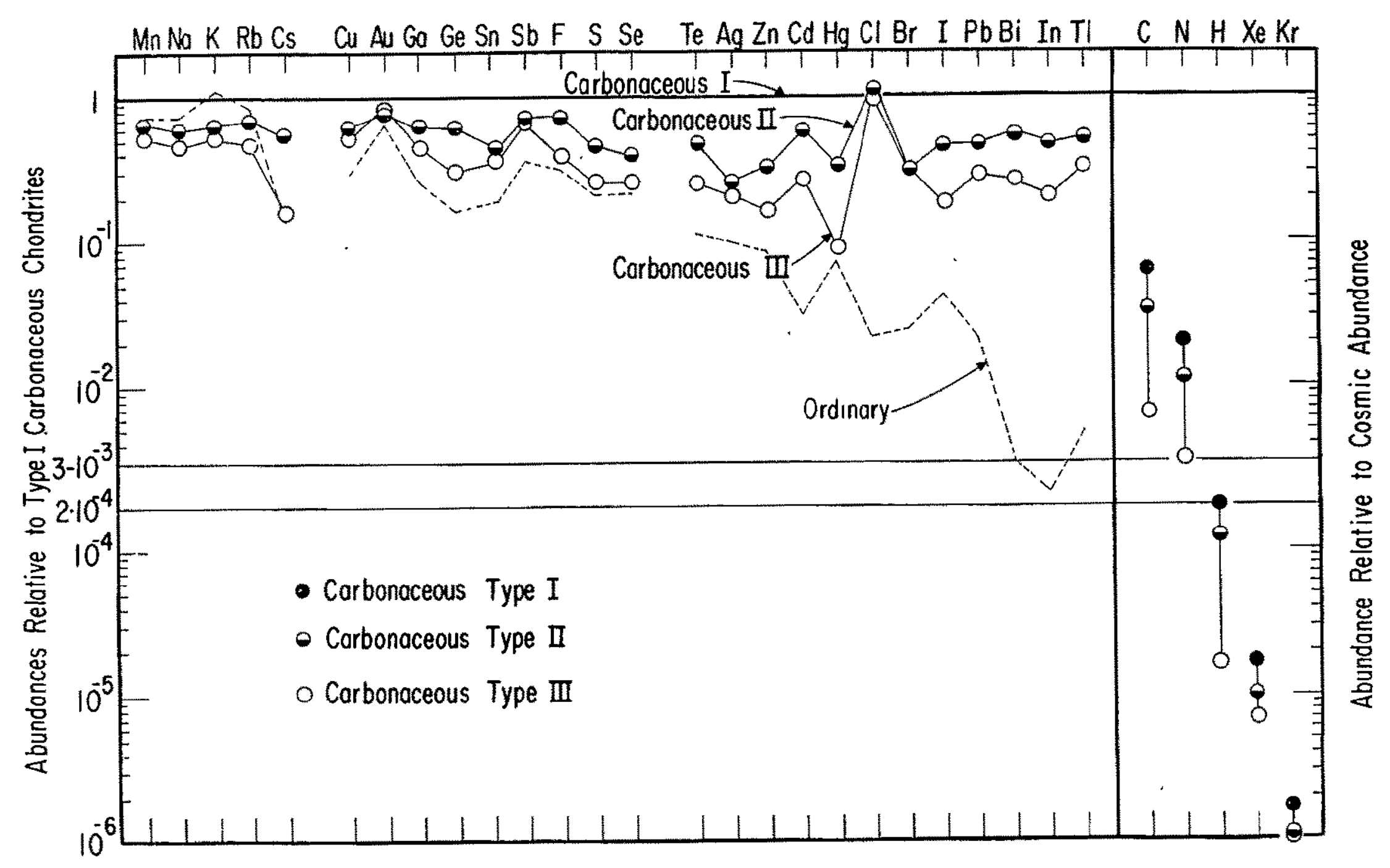

Fig. 2 


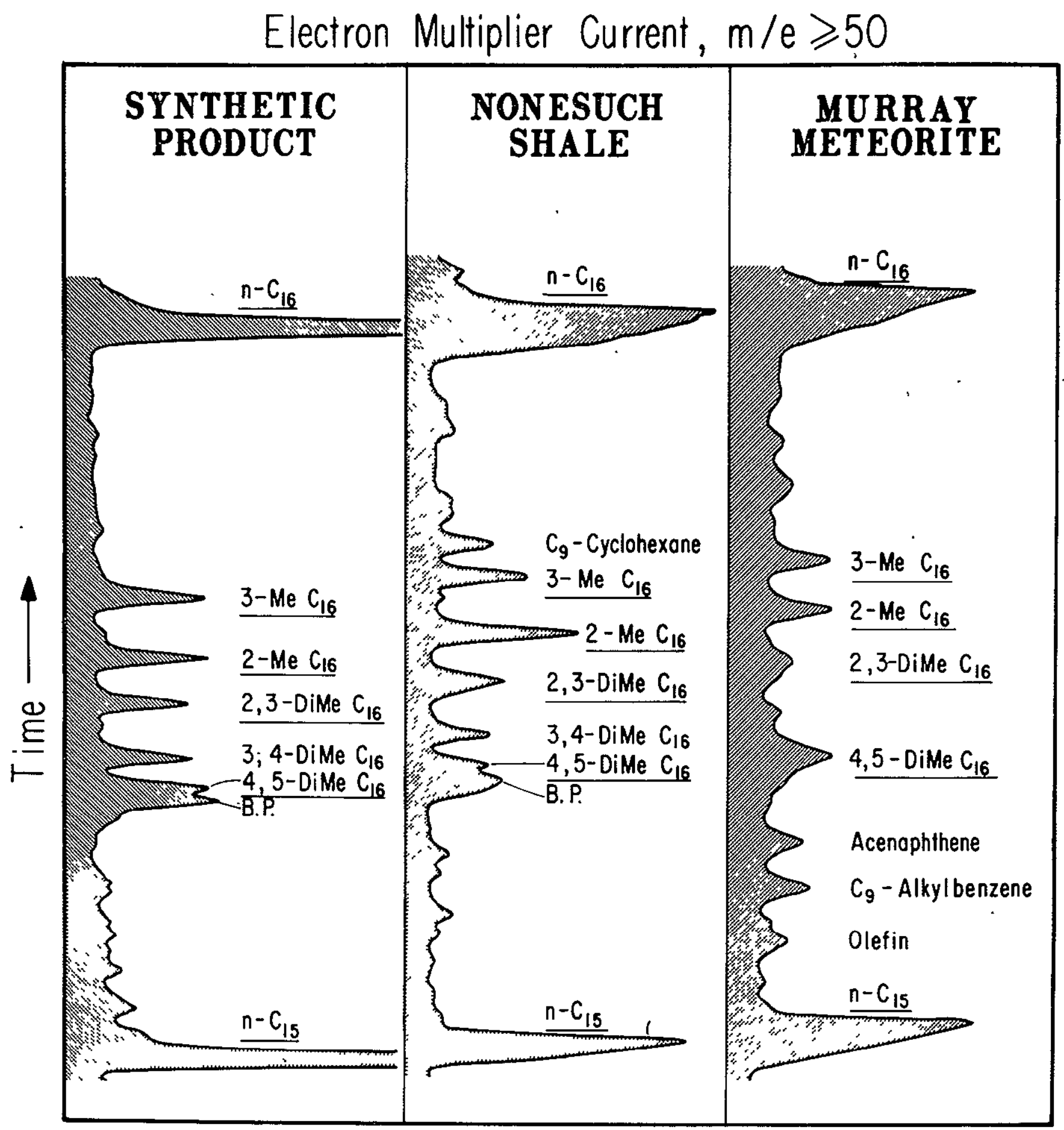

Fig.3 